\title{
Continuum of Host-Gut Microbial Co-metabolism: Host CYP3A4/3A7 are Responsible for Tertiary Oxidations of Deoxycholate Species ${ }^{\mathbb{}}$
}

\author{
Jian Zhang, ${ }^{1}$ Ling-Zhi Gao, ${ }^{1}$ Yu-Jie Chen, Ping-Ping Zhu, Shan-Shan Yin, Ming-Ming Su, Yan Ni, \\ Jia Miao, Wen-Lin Wu, Hong Chen, Kim L. R. Brouwer, Chang-Xiao Liu, Liang Xu, Wei Jia, \\ and Ke Lan
}

Key Laboratory of Drug-Targeting and Drug Delivery System of the Education Ministry, West China School of Pharmacy, Sichuan University, Chengdu, China (J.Z., L.Z.G., Y.J.C., P.P.Z., S.S.Y., L.X., K.L.); Metabolomics Shared Resource, University of Hawaii Cancer Center, Honolulu, Hawaii (M.M.S., Y.N., W.J.); Institute of Clinical Pharmacology, West China Hospital, Sichuan University, Chengdu, China (J.M.); Chengdu Institutes for Food and Drug Control, Chengdu, China (W.L.W., H.C.); UNC Eshelman School of Pharmacy, University of North Carolina at Chapel Hill, North Carolina (K.L.R.B.); State Key Laboratory of Drug Delivery Technology and Pharmacokinetics, Tianjin Institute of Pharmaceutical Research, Tianjin, China (C.X.L.); and Chengdu Health-Balance Medical Technology Co., Ltd., Chengdu, China (S.S.Y.)

Received November 26, 2018; accepted December 31, 2018

\begin{abstract}
The gut microbiota modifies endogenous primary bile acids (BAs) to produce exogenous secondary BAs, which may be further metabolized by cytochrome P450 enzymes (P450s). Our primary aim was to examine how the host adapts to the stress of microbe-derived secondary BAs by P450-mediated oxidative modifications on the steroid nucleus. Five unconjugated tri-hydroxyl BAs that were structurally and/or biologically associated with deoxycholate (DCA) were determined in human biologic samples by liquid chromatographytandem mass spectrometry in combination with enzyme-digestion

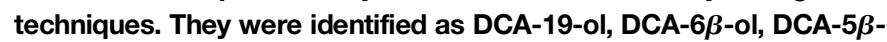
ol, DCA- $6 \alpha$-ol, DCA-1 $\beta$-ol, and DCA- $4 \beta$-ol based on matching
\end{abstract}

in-laboratory synthesized standards. Metabolic inhibition assays in human liver microsomes and recombinant $\mathrm{P} 450$ assays revealed that CYP3A4 and CYP3A7 were responsible for the regioselective oxidations of both DCA and its conjugated forms, glycodeoxycholate (GDCA) and taurodeoxycholate (TDCA). The modification of secondary BAs to tertiary BAs defines a host liver (primary BAs)-gut microbiota (secondary BAs)-host liver (tertiary BAs) axis. The regioselective oxidations of DCA, GDCA, and TDCA by CYP3A4 and CYP3A7 may help eliminate host-toxic DCA species. The 19- and $4 \beta$-hydroxylation of DCA species demonstrated outstanding CYP3A7 selectivity and may be useful as indicators of CYP3A7 activity.

\section{Introduction}

The drug-metabolizing enzyme (DME) genes are a group of environmental susceptibility genes that have existed on this planet for billions of years (Nebert et al., 1988; Gonzalez and Nebert, 1990),

This study was supported, in part, by National Institute of General Medical Sciences of the National Institutes of Health $(\mathrm{NIH})$ under award no. R01 [GM041935] and R35 [GM122576].

${ }^{1}$ J.Z. and L.-Z.G. contributed equally to this work.

https://doi.org/10.1124/dmd.118.085670.

S This article has supplemental material available at dmd.aspetjournals.org. long predating the use of drugs. The expression and activity of these DME genes are decisive in defining our susceptibility to toxic substances or diseases. Based on the roles of nuclear receptors, also known as xenobiotic sensors, that modulate DMEs in growth signal transduction pathways, Nebert $(1990,1991)$ proposed in 1990 that DMEs are responsible for controlling the steady-state levels of small organic, oxygenated molecules that act as signals for growth, differentiation, virulence, and even tumor promotion. Examples of DME functions beyond drug metabolism are manifested in the synthesis and disposition of steroid hormones by human cytochrome P450 enzymes (P450s). In this current era of metagenomics, it remains

ABBREVIATIONS: 3-dehydroCA, $7 \alpha, 12 \alpha$-dihydroxy-3-oxo-5 $\beta$-cholan-24-oic acid; 3-dehydroCDCA, $7 \alpha$-hydroxy-3-oxo-5 $\beta$-cholan-24-oic acid; 3dehydroDCA, $12 \alpha$-hydroxy-3-oxo-5 $\beta$-cholan-24-oic acid; 3-dehydroLCA, 3-oxo-5 $\beta$-cholan-24-oic acid; 3-deoxyCA, $7 \alpha, 12 \alpha$-dihydroxy-5 $\beta$ cholan-24-oic acid; 12 -epiCA, $3 \alpha, 7 \alpha, 12 \beta$-trihydroxy-5 $\beta$-cholan-24-oic acid; 12 -epiDCA, $3 \alpha, 12 \beta$-dihydroxy-5 $\beta$-cholan-24-oic acid; AUC, area under the curve; BA, bile acids; bai genes, bile acid-inducible genes CA, cholate, $3 \alpha, 7 \alpha, 12 \alpha$-trihydroxy-5 $\beta$-cholan-24-oic acid; CDCA, chenodeoxycholate, $3 \alpha, 7 \alpha$-dihydroxy-5 $\beta$-cholan-24-oic acid; DCA, deoxycholate, $3 \alpha, 12 \alpha$-dihydroxy-5 $\beta$-cholan-24-oic acid; DCA-19-ol, $3 \alpha, 12 \alpha, 19$-trihydroxy-5 $\beta$-cholan-24-oic acid; DCA-6 $\alpha$-ol, $3 \alpha, 6 \alpha, 12 \alpha$-trihydroxy-5 $\beta$-cholan-24-oic acid; DCA- $1 \beta$-ol, $1 \beta, 3 \alpha, 12 \alpha-$ trihydroxy- $5 \beta$ cholan-24-oic acid; DCA- $2 \beta$-ol, $2 \beta, 3 \alpha, 12 \alpha$-trihydroxy- $5 \beta$-cholan-24-oic acid; DCA- $4 \beta$-ol, $3 \alpha, 4 \beta, 12 \alpha$-trihydroxy-5 $\beta$-cholan-24-oic acid; DCA$5 \beta$-ol, $3 \alpha, 5 \beta, 12 \alpha$-trihydroxy-5 $\beta$-cholan-24-oic acid; DCA- $6 \beta$-ol, $3 \alpha, 6 \beta, 12 \alpha$-trihydroxy- $5 \beta$-cholan-24-oic acid; DME, drug-metabolizing enzyme; DMSO, dimethylsulfoxide; GDCA, glycodeoxycholate; $\alpha \mathrm{HCA}, \alpha$-hyocholate, $3 \alpha, 6 \alpha, 7 \alpha$-trihydroxy-5 $\beta$-cholan-24-oic acid; $\beta \mathrm{HCA}, \beta$-hyocholate, $3 \alpha, 6 \alpha, 7 \beta$-trihydroxy- $5 \beta$-cholan-24-oic acid; HDCA, hyodeoxycholate, $3 \alpha, 6 \alpha$-dihydroxy- $5 \beta$-cholan- 24 -oic acid; isoCA, isocholate, $3 \beta, 7 \alpha, 12 \alpha$ trihydroxy-5 $\beta$-cholan-24-oic acid; isoDCA, $3 \beta, 12 \alpha$-dihydroxy-5 $\beta$-cholan-24-oic acid; isoHDCA, $3 \beta, 6 \alpha$-dihydroxy-5 $\beta$-cholan-24-oic acid; isoUCA, $3 \beta, 7 \beta, 12 \alpha$-trihydroxy-5 $\beta$-cholan-24-oic acid; isoUDCA, $3 \beta, 7 \beta$-dihydroxy-5 $\beta$-cholan-24-oic acid; LCA, lithocholate, $3 \alpha$-hydroxy-5 $\beta$-cholan-24-oic acid; LC-MS/MS, liquid chromatography-tandem mass spectrometry; MDCA, $3 \alpha, 6 \beta$-dihydroxy-5 $\beta$-cholan-24-oic acid; NMR, nuclear magnetic resonance; P450, cytochrome P450; rP450, recombinant human cytochrome P450; TDCA, taurodeoxycholate; UCA, ursocholate, $3 \alpha, 7 \beta, 12 \alpha-$ trihydroxy- $5 \beta$-cholan-24-oic acid; UDCA, ursodeoxycholate, $3 \alpha, 7 \beta$-dihydroxy- $5 \beta$-cholan-24-oic acid; UGT, UDP-glucuronosyltransferase. 
poorly understood whether and how P450s participate in the host-gut microbial co-metabolism networks. Such an inquiry is intriguing because the microbiota-derived small molecules are "exogenous" to the host genome, may be candidates for metabolism by P450s, and might be mediators of important microbe-host metabolic interactions (Donia and Fischbach, 2015).

Bile acids (BAs) are an important class of metabolites that undergo cometabolism by host and symbiotic gut microbiota. BA-mediated host-gut microbial crosstalk is important for maintaining a healthy gut microbiota (Theriot et al., 2014; Buffie et al., 2015), balanced lipid and carbohydrate metabolism (de Aguiar Vallim et al., 2013; Wahlström et al., 2016), insulin sensitivity (Maruyama et al., 2002; Kawamata et al., 2003), and innate immunity (Inagaki et al., 2006; Vavassori et al., 2009). Within the BA metabolic network, much attention has been given to defining the hepatic biosynthesis of the primary BAs CDCA and CA (Russell, 2003) and the 7-dehydroxylation of primary BAs by bacteria with bile acidinducible (bai) genes as secondary BAs, lithocholate (LCA) and DCA (Ridlon et al., 2006; Dawson and Karpen, 2015). In contrast, tertiary BA metabolism, which may be termed the redox modification on the steroid skeleton of secondary BAs by the host, remains underinvestigated. The unclear pathways are fundamentally associated with how the host dynamically adapts to the stress of the more host-toxic secondary BA stress, along with the colonization, development, homeostasis, and dysbiosis of gut microbiota.

In the last century, several unusual BAs with hydroxylation sites at $\mathrm{C}-1,-2,-4,-6$, and -19 have been identified by gas chromatographymass spectrometry in humans (Sjövall et al., 2010). Among them, two pathways, $6 \alpha$-hydroxylation of LCA as hyodeoxycholate (HDCA) (Trülzsch et al., 1974; Araya and Wikvall, 1999; Deo and Bandiera, 2009 ) and $1 \beta$-hydroxylation of DCA as DCA- $1 \beta$-ol (Gustafsson et al., 1985; Bodin et al., 2005; Hayes et al., 2016), were found to be catalyzed by CYP3A. Thus, HDCA and DCA- $1 \beta$-ol may be considered tertiary BAs. The other unusual BA species are seldom detected and discussed in recent literature. We developed a liquid chromatography-tandem mass spectrometry (LC-MS/MS) method for the analysis of the human BA metabolome and have been able to detect several new unconjugated tri-hydroxyl BAs in adult human serum and urine samples. In this work, we determined that these tertiary BA species are uniquely derived from the oxidation metabolism of DCA, glycodeoxycholate (GDCA), and taurodeoxycholate (TDCA). The P450 enzymes CYP3A4 and CYP3A7 were shown to be exclusively responsible, in a regioselective manner, for the relevant oxidation reactions. This finding has provided a new landscape for the functional biology of CYP3A, one of the most important DMEs, in the host-gut microbial cometabolism of BAs in human.

\section{Materials and Methods}

Materials and Reagents. The BA standards obtained from Steraloids (Newport, RI), TRC (Toronto, Canada), Santa Cruz (Dallas, TX), or SigmaAldrich (St. Louis, MO) are summarized in Supplemental Table S1. The P450 inhibitors were obtained from TCI (Nihonbashi-honcho, Chuo-ku, Japan), TRC, Santa Cruz, or Sigma-Aldrich. Sulfatase from Helix pomatia type $\mathrm{H}-1, \beta$-glucuronidase from Helix pomatia type $\mathrm{H}-1$, and choloylglycine hydrolase from clostridium perfringens were purchased from SigmaAldrich. Human liver microsomes from 150 mixed-gender pooled donors, human intestinal microsomes from seven mixed-gender pooled donors, NADPH-regenerating system solution A (NADPH-A, containing $26 \mathrm{mM}$ $\mathrm{NADP}^{+}, 66 \mathrm{mM}$ glucose-6-phosphate and $66 \mathrm{mM} \mathrm{MgCl}_{2}$ in water), NADPHregenerating system solution $\mathrm{B}$ (NADPH-B, containing $40 \mathrm{U} / \mathrm{ml}$ glucose6-phosphate dehydrogenase in $5 \mathrm{mM}$ sodium citrate), and $0.5 \mathrm{M}, \mathrm{pH} 7.4$, taurodeoxycholate (TDCA) were purchased from Corning (Tewksbury, MA). Human kidney microsomes from five mixed-gender pooled donors were obtained from BioIVT (West Sussex, UK). Recombinant human cytochrome P450 enzymes (rP450s) prepared from baculovirus-transfected insect cells (Supersomes), including 1A2, 1B1, 2A6, 2B6, 2C8, 2C9*1, 2C18, 2C19, 2D6*1, 3A4, 3A5, 3A7, 2E1, 2J2, 4A11, 4F2, 4F3B, and 4F12, were purchased from Corning. Another set of rP450s, prepared from plasmid-transfected Escherichia coli (Bactosomes), including 2B6, 2C8, 2C9, 2C19, 2D6, 3A4, 3A5, and 3A7, were obtained from Cypex Ltd. (Dundee, Scotland). Sodium acetate, glacial acetic acid, and LC-MS grade methanol, acetonitrile, and formic acid were purchased from Sigma-Aldrich. Dimethylsulfoxide (DMSO) was purchased from Thermo Fisher Scientific (Waltham, MA). Ultrapure water was obtained by using a Milli-Q system (Millipore, Bedford, UK).

Synthesis of DCA-19-ol. We synthesized $3 \alpha, 12 \alpha$, 19-trihydroxy-5 $\beta$-cholan24-oic acid (DCA-19-ol, CAS 171524-54-2) from CA according to the same procedure described in reference (Kurosawa et al., 1995). The LC-MS/MS and nuclear magnetic resonance (NMR) data of DCA-19-ol are summarized in Supplemental Fig. S1. The following are the spectra data for the methyl $3 \alpha, 12 \alpha$, 19-triacetoxy-5 $\beta$-cholanoate: ${ }^{1} \mathbf{H}-\mathbf{N M R}\left(400 \mathrm{MHz}, \mathrm{CDCl}_{3}\right) \delta 5.07(\mathrm{~m}, 1 \mathrm{H}), 4.71$ (brm, 1H), $3.83(\mathrm{~m}, 1 \mathrm{H}), 4.31(\mathrm{~d}, 1 \mathrm{H}, J=11 \mathrm{~Hz}), 3.94(\mathrm{~d}, 1 \mathrm{H}, J=11 \mathrm{~Hz}), 3.66$ $(\mathrm{s}, 3 \mathrm{H}), 0.82(\mathrm{~d}, 3 \mathrm{H}, J=6 \mathrm{~Hz}), 0.73(\mathrm{~s}, 3 \mathrm{H})$.

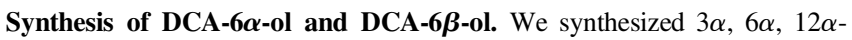
trihydroxy-5 $\beta$-cholan-24-oic acid (DCA-6 $\alpha$-ol, CAS 21066-18-2), and $3 \alpha, 6 \beta$, $12 \alpha$-trihydroxy-5 $\beta$-cholan-24-oic acid (DCA-6 $\beta$-ol, CAS 63266-90-0) from CA using the same procedure described in reference (Iida et al., 1991b). The LC-MS/MS and NMR data of DCA- $6 \beta$-ol and DCA- $6 \alpha$-ol are summarized in Supplemental Fig. S2 and S3, respectively. The following are the spectra data for the methyl $3 \alpha, 6 \alpha, 12 \alpha$-trihydroxy-5 $\beta$-cholanoate: ${ }^{\mathbf{1}} \mathbf{H}$-NMR $\left(600 \mathrm{MHz}, \mathrm{CDCl}_{3}\right)$ $\delta 4.05$ (brm, 1H), $3.99(\mathrm{~m}, 1 \mathrm{H}), 3.66$ (s, 3H), 3.63 (brm, 1H), 0.97 (d, 3H, $J=6 \mathrm{~Hz}), 0.89(\mathrm{~s}, 3 \mathrm{H}), 0.66(\mathrm{~s}, 3 \mathrm{H})$; and for ${ }^{13} \mathbf{C}-\mathbf{N M R}\left(101 \mathrm{MHz}, \mathrm{CDCl}_{3}\right) \delta$ $174.8,72.9,71.7,68.0,51.5,48.3,47.6,47.1,46.5,35.5,35.5,35.1,34.9$, $34.4,32.8,31.1,30.8,29.7,28.7,28.4,27.4,23.6,23.1,17.2$, and 12.6. The following are the spectra data for the methyl $3 \alpha, 6 \beta, 12 \alpha$-trihydroxy$5 \beta$-cholanoate: ${ }^{\mathbf{1}} \mathbf{H}$-NMR $\left(400 \mathrm{MHz}, \mathrm{CDCl}_{3}\right) \delta 4.00(\mathrm{~m}, 1 \mathrm{H}), 3.77(\mathrm{~m}, 1 \mathrm{H})$, $3.66(\mathrm{~s}, 3 \mathrm{H}), 3.61(\mathrm{brm}, 1 \mathrm{H}), 1.09(\mathrm{~s}, 3 \mathrm{H}), 0.97(\mathrm{~d}, 3 \mathrm{H}, J=6 \mathrm{~Hz}), 0.71(\mathrm{~s}, 3 \mathrm{H})$; and for ${ }^{13} \mathbf{C}$-NMR $\left(151 \mathrm{MHz}, \mathrm{CDCl}_{3}\right) \delta 174.7,73.0,72.9,71.1,51.5,48.4$, 47.8 , 47.2, 46.4, 36.2, 35.6, 35.1, 34.2, 33.8, 33.8, 31.0, 30.8, 29.86, 28.3, 27.4, 25.2, 23.6, 17.2, and 12.7.

Synthesis of DCA-5 $\boldsymbol{\beta}$-ol. We synthesized $3 \alpha, 5 \beta, 12 \alpha$-trihydroxy-cholan24-oic acid (DCA-5 $\beta$-ol, CAS 58678-36-7) were synthesized from DCA according to the same procedure described in reference (Iida et al., 2001). The LC-MS/MS and NMR data of DCA- $5 \beta$-ol were summarized in Supplemental Fig. S4. The following are the spectra data for the methyl $3 \alpha, 12 \alpha$-diacetoxy$5 \beta$-hydroxy cholanoate: ${ }^{\mathbf{1}} \mathbf{H}$-NMR $\left(400 \mathrm{MHz} \mathrm{CDCl}_{3}\right) \delta 5.09(\mathrm{~m}, 1 \mathrm{H}), 5.05$ (brm, 1H), $3.66(\mathrm{~s}, 3 \mathrm{H}), 0.88(\mathrm{~s}, 3 \mathrm{H}), 0.81(\mathrm{~d}, 3 \mathrm{H}, J=6 \mathrm{~Hz})$, and $0.73(\mathrm{~s}, 3 \mathrm{H})$.

Synthesis of DCA-1 $\beta$-ol. We synthesized $1 \beta, 3 \alpha, 12 \alpha$-trihydroxy- $5 \beta$-cholan24-oic acid (DCA-1 $\beta$-ol, CAS 80434-32-8) from DCA according to the same procedure described in Hayes et al. (2017). The LC-MS/MS and NMR data of DCA-1 $\beta$-ol were summarized in Supplemental Fig. S5. The following are the spectra data for the methyl $1 \beta, 3 \alpha$-dihydroxy- $12 \alpha$-acetoxy-5 $\beta$-cholanoate: ${ }^{1} \mathbf{H}$-NMR $\left(400 \mathrm{MHz} \mathrm{CDCl}_{3}\right) \delta 5.04(\mathrm{~m}, 1 \mathrm{H}), 4.09(\mathrm{brm}, 1 \mathrm{H}), 3.83(\mathrm{~m}, 1 \mathrm{H})$, $3.66(\mathrm{~s}, 3 \mathrm{H}), 2.08(\mathrm{~s}, 3 \mathrm{H}), 1.03(\mathrm{~s}, 3 \mathrm{H})$, and $0.73(\mathrm{~s}, 3 \mathrm{H})$.

Synthesis of DCA-2 $\beta$-ol and DCA-4 $\beta$-ol. We synthesized $2 \beta, 3 \alpha, 12 \alpha-$ trihydroxy-5 $\beta$-cholan-24-oic acid (DCA- $2 \beta$-ol, CAS 133565-88-5), and $3 \alpha, 4 \beta$, $12 \alpha$-trihydroxy-5 $\beta$-cholan-24-oic acid (DCA-4 $\beta$-ol, CAS 129012-50-6) from DCA according to the same procedure described in references (Iida et al., 1989, 1991a). The LC-MS/MS and NMR data of DCA-4 $\beta$-ol are summarized in Supplemental Fig. S6. The following are the spectra data for the methyl $2 \beta$, $3 \alpha$-dihydroxy-12 $\alpha$-acetoxy-5 $\beta$-cholanoate: ${ }^{\mathbf{1}} \mathbf{H}$-NMR $\left(400 \mathrm{MHz}, \mathrm{CDCl}_{3}\right)$ $\delta 5.09(\mathrm{~m}, 1 \mathrm{H}), 3.66(\mathrm{~s}, 3 \mathrm{H}), 3.43(\mathrm{brm}, 1 \mathrm{H}), 3.35$ (brm, 1H), $0.94(\mathrm{~s}, 3 \mathrm{H})$, $0.79(\mathrm{~d}, 3 \mathrm{H}, J=6 \mathrm{~Hz})$, and $0.72(\mathrm{~s}, 3 \mathrm{H}),{ }^{13} \mathbf{C}-\mathbf{N M R}\left(151 \mathrm{MHz}, \mathrm{CDCl}_{3}\right) \delta 174.6$, 170.6, 76.5, 75.8, 71.3, 51.5, 49.1, 47.5, 44.9, 43.1, 41.8, 36.7, 35.9, 35.7, 34.6, 33.6, 30.9, 30.7, 27.3, 26.3, 25.9, 25.8, 23.4, 23.0, 21.4, 17.5, and 12.3. The following are the spectra data for the methyl $3 \alpha, 4 \beta$-dihydroxy- $12 \alpha$ acetoxy-5 $\beta$-cholanoate: ${ }^{1} \mathbf{H}-\mathbf{N M R}\left(400 \mathrm{MHz} \mathrm{CDCl}_{3}\right) \delta 5.05(\mathrm{~m}, 1 \mathrm{H}), 3.72$ (dd, 1H, $J=9 \mathrm{~Hz}, 10 \mathrm{~Hz}$ ), 3.66 (s, 3H), 3.39 (brm, 1H), 0.93 (s, 3H), 0.79 $(\mathrm{d}, 3 \mathrm{H}, J=6 \mathrm{~Hz})$, and $0.72(\mathrm{~s}, 3 \mathrm{H}) ;{ }^{13} \mathrm{C}-\mathbf{N M R}\left(151 \mathrm{MHz}, \mathrm{CDCl}_{3}\right) \delta 174.6$, $170.5,76.5,75.7,72.4,51.5,49.4,48.4,47.5,44.9,36.4,36.2,35.5,34.6,34.1$, $30.9,30.7,27.2,27.1,25.6,25.5,23.3,23.2,21.3,20.7,17.4$, and 12.3. 
Human Serum and Urine. Postprandial human serum and urine were collected from 13 healthy adult volunteers (Ferslew et al., 2015). After ingestion of the standardized high-fat breakfast, urine samples were collected and pooled over the 2-hour period; blood samples were collected in untreated glass tubes at 0.0 , $0.5,1.0,1.5$, and 2.0 hours and allowed to clot for 30-60 minutes to separate the serum. This study was approved by the University of North Carolina at Chapel Hill (UNC-CH) Biomedical Institutional Review Board and published in ClinicalTrials. gov (NCT01766960). Overnight fasting spot urine samples were collected at West China Hospital of Sichuan University from 45 healthy volunteers including 30 men and 15 women (18-40 years old, body mass index 19-26). Briefly, the inclusion criteria for healthy subjects were normal blood, liver and kidney functions; negative test results for the biomarker of infectious diseases including hepatitis B, hepatitis C, HIV and Treponema pallidum; no abnormalities in electrocardiogram, abdominal ultrasonography and chest radiography; no history of gastrointestinal surgery except for appendicectomy; and no ingestion of any medications or dietary supplements 2 weeks before urine collections. The studies were approved by the Institutional Review Board of West China Hospital of Sichuan University. All serum and urine samples were stored at $-80^{\circ} \mathrm{C}$ until analysis.

Sample Preparation for BAs Analysis. Analysis of BAs metabolome were performed using the enzyme digestion techniques published in our recent work (Zhu et al., 2018). For the postprandial human serum and urine samples from 13 healthy adults, aliquot $(50 \mu \mathrm{l})$ was transferred to $700-\mu 1$ round-well 96-well plate in quadruplicate. The first aliquot was prepared with treatment-1 (T1) in which $150 \mu$ l of sodium acetate buffer ( $\mathrm{pH}$ 5.0) was added. T1 treatment without the use of enzymes was designed to determine the free unconjugated form. The second aliquot was prepared with treatment 2 (T2), in which $150 \mu 1$ of buffer containing $100 \mathrm{U}$ of choloylglycine hydrolase was added to deconjugate the $\mathrm{N}$-acylamidated forms. The third aliquot was prepared with treatment 3 (T3), in which $150 \mu \mathrm{l}$ of buffer containing $50 \mathrm{U}$ of sulfatase and $500 \mathrm{U}$ of $\beta$-glucuronidase was added to hydrolyze sulfates and glucuronides. The final aliquot was prepared with treatment 4 (T4), in which $150 \mu$ l of buffer containing all three enzymes was added. In brief, the free unconjugated form (Free) was always detected in T1-T4; glycine-/taurine-conjugates were combinedly observed in T2; sulfates/glucuronides were combinedly detected in T3; glycine/ taurine conjugates, sulfates/glucuronides, and "double-conjugates" linked with both glycine/taurine and sulfate/glucuronide were collectively detected in T4 (Total). The fasting spot-urine samples were prepared and determined only with T4 treatment. The calibration and quality control samples were prepared with $\mathrm{T} 1$ treatment. The plate was incubated at $37^{\circ} \mathrm{C}$ for 6 hours and subsequently lyophilized. In each well, $200 \mu \mathrm{l}$ of acetonitrile containing $1 \%$ formic acid and $100 \mathrm{nM}$ internal standards (LCA-2,2,4,4-D4, DCA-2,2,4,4-D4, UDCA2,2,4,4-D4, and CA-2,2,4,4-D4) was added in each well. The plate was vortexmixed at $1500 \mathrm{rpm}$ at $10^{\circ} \mathrm{C}$ for 30 minutes and centrifuged at $4^{\circ} \mathrm{C}$ at $3000 \mathrm{~g}$ for 20 minutes. Two hundred microliters of supernatant was vacuum-evaporated at $30^{\circ} \mathrm{C}$. The residue was reconstituted with $50 \mu 1$ of acetonitrile and $50 \mu 1$ water by vortex-mixing at $10^{\circ} \mathrm{C}$ at $900 \mathrm{rpm}$ for 20 minutes. After centrifuge, the plate was placed into autosampler for subsequent analysis.

Quantitative LC-MS/MS Analysis. Quantitative analysis of unconjugated BAs was performed using the method published in our recent work on ACQUITY ultraperformance LC coupled to a Xevo TQ-S MS (Waters, Milford, MA) (Yin et al., 2017; Zhu et al., 2018). The mobile phases consisted of $0.01 \%$ formic acid in water (mobile phase A) and acetonitrile (mobile phase B). Five microliters of each sample was injected onto an ACQUITY BEH C18 column $(1.7 \mu \mathrm{m}$, $100 \times 2.1 \mathrm{~mm}$ ) (Waters). The flow rate was $0.45 \mathrm{ml} / \mathrm{min}$ with the following mobile phase gradient: $0.0-0.5(95 \% \mathrm{~A}), 0.5-1.0(95 \%-64 \% \mathrm{~A}), 1.0-2.0(64 \%-74 \% \mathrm{~A})$, $2.0-4.0(74 \%-70 \%$ A), 4.0-6.0 (70\% A), 6.0-7.0 (70\%-62\% A), 7.0-9.0 (62\%-55\% A), 9.0-12.5 (55\%-30\% A), 12.5-13.0 (30\%-0\% A), $13.0-14.0$ (0\% A) and 14.0-14.1 (0\%-95\% A), and 14.1-15.0 minutes (95\% A). The "unusual" gradient used a fast elution with 0.5-1.0 minute to ensure a 15-minute throughput. The decreased elution within 1.0-6.0 minutes was purposefully optimized to separate $\beta \mathrm{HCA}$, isoCA, and TBA13 (DCA- $1 \beta$-ol), as discussed in our recent publications (Yin et al., 2017; Zhu et al., 2018). It was because of the slowest elution within 4.0-6.0 minutes that the peaks eluted approximately within the time window demonstrated a slightly broadened peak compared with the other peaks. The mass spectrometer was operated in the negative mode with a $3.0-\mathrm{kV}$ capillary voltage. The source and desolvation temperatures were set at 150 and $550^{\circ} \mathrm{C}$, respectively. Nitrogen and argon were used as cone and collision gases, respectively. The cone gas flow and desolvation gas flow were set at 150 and
950 liters/hour, respectively. The selected ion recording and multiple reaction monitoring transitions used in this work are summarized in Supplemental Table S1.

High-Definition MS/MS Analysis. High-definition MS/MS spectra of the synthesized standards were compared with those of metabolites captured in vivo or in vitro. The analysis was performed on the Vanquish ultra-highperformance liquid chromatography system connected to the Q-Exactive Plus Orbitrap (Thermo Fisher Scientific, Schwerte, Germany) by using the same chromatographic method and the similar source parameters as the LC-MS/MS method. Full-scan MS spectra were scanned within $\mathrm{m} / z$, 100-500 at a resolution of 70,000, automatic gain control (AGC) target at $3 \times 10^{6}$ ions, maximum ion injection time (IT) at 100 milliseconds; dd-MS ${ }^{2}$ within $m / z 50-435$ were acquired for $\left[\mathrm{C}_{24} \mathrm{H}_{39} \mathrm{O}_{5}\right]^{-}$at a resolution of 17,500 , AGC target at $1 \times 10^{5}$ ions, maximum IT at 50 milliseconds, and HCD collision energy of $50 \mathrm{eV}$

In Vitro Metabolism Studies of BAs. In vitro metabolisms of BAs were performed according to the guidelines released by Corning. In brief, the working solutions were prepared in DMSO at a concentration of $10.0 \mathrm{mM}$ for all BA substrates except for LCA $(4.0 \mathrm{mM})$. The working solutions of selective P450 inhibitors were prepared in DMSO at the preset concentrations, including ketoconazole $(100 \mu \mathrm{M})$, fluconazole $(2.0 \mathrm{mM})$, diethyldithiocarbamate (DEDC, $4.0 \mathrm{mM})$, quinidine $(200 \mu \mathrm{M})$, nootkatone $(200 \mu \mathrm{M})$, sulfaphenazole $(200 \mu \mathrm{M})$, quercetin $(200 \mu \mathrm{M})$, montelukast $(100 \mu \mathrm{M})$, sertraline $(2.0 \mathrm{mM})$, trans-2-phenylcyclopropylamine (2-PCPA, $40 \mu \mathrm{M})$, and $\alpha$-naphthoflavone $(\alpha-\mathrm{NF}, 20 \mu \mathrm{M})$. The working solutions of time-dependent inhibitors were also prepared in DMSO, including verapamil $(5.0 \mathrm{mM})$, paroxetine $(2.0 \mathrm{mM})$, ticlopidine $(200 \mu \mathrm{M})$, tienilic acid $(2.0 \mathrm{mM})$, phenelzine $(200 \mu \mathrm{M})$, thio-TEPA $(1.0 \mathrm{mM})$, and furafylline $(200 \mu \mathrm{M})$. Incubation with an initial substrate concentration of $50 \mu \mathrm{M}(20 \mu \mathrm{M}$ for LCA $)$ was performed on 96 -well plates in a shaking incubator at $37^{\circ} \mathrm{C}$. The total incubation volume was $100 \mu \mathrm{l}$, containing $5.0 \mu \mathrm{l}$ of NADPH-A, $1.0 \mu \mathrm{l}$ of NADPH-B, $0.5 \mu \mathrm{l}$ of working solution of BA substrates, $0.5 \mu 1$ of working solution of inhibitors or blank solvent, and $2.5 \mu \mathrm{l}$ of microsomes (protein concentration of $20 \mathrm{mg} / \mathrm{ml}$ ) or rP450s $(1.0 \mathrm{nmol}$

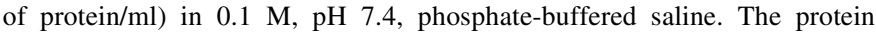
concentration in the incubation media was $0.5 \mathrm{mg} / \mathrm{ml}$ for microsomes or $50 \mathrm{pmol} / \mathrm{ml}$ for $\mathrm{rP} 450 \mathrm{~s}$. All incubations were performed in triplicate. For the inhibition assay using selective $\mathrm{P} 450$ inhibitors, the reactions were initiated by adding enzymes (microsomes or rP450s) after a preincubation at $37^{\circ} \mathrm{C}$ for 5 minutes. For the inhibition assay using time-dependent P450 inhibitors, the reactions were initiated by adding working solution of BA substrates after a preincubation at $37^{\circ} \mathrm{C}$ for 30 minutes. The reactions were stopped at a preset time point by adding $300 \mu \mathrm{l}$ of ice-cold acetonitrile containing $0.1 \%$ formic acid and $50 \mu \mathrm{M}$ CA-2,2,4,4-D4 as an internal standard. The reaction mixture was then centrifuged at $4^{\circ} \mathrm{C}$ at $4000 \mathrm{~g}$ for 20 minutes. For incubations using unconjugated BAs as substrates, the supernatant $(50 \mu \mathrm{l})$ was diluted with an equal volume of water and subjected to LC-MS/MS analysis. For incubations using GDCA or TDCA as substrates, the supernatant was vacuum-evaporated and prepared according to the enzyme digestion technique of $\mathrm{T} 2$ to hydrolyze and analyze the oxidized metabolites in their unconjugated forms.

Data Processing. The LC-MS/MS raw data were processed by MassLynx (V4.1; Waters) and UNIFI (V1.8; Waters). DCA-19-ol, DCA-6 $\beta$-ol, DCA- $5 \beta$-ol, DCA- $6 \alpha-$ ol, DCA- $1 \beta$-ol, and DCA- $4 \beta$-ol were semiquantified using the calibration curve for $\mathrm{CA}$ because they produced equivalent responses at the same level at selective ion recording of $407>407$. The high-definition MS/MS raw data were processed by Xcalibur (V4.2; Thermo Fisher Scientific, San Jose, CA). The MS/MS spectrum of each BA was obtained by combining the scans within the peak width. Multivariate analysis of the total urinary BA profiles was carried out using SIMCA $\mathrm{P}^{+}$(v13; Umetrics, Umeå, Sweden) and R software (version 2.15.0, www.r-project.org). Analysis of in vitro metabolism data was performed using GraphPad prism (version 7.0; GraphPad software, La Jolla, CA). The apparent renal clearance was calculated with the $0-2$ hours total urinary excretion amount (nanomole)/the $0-2$ hours total serum area under curve (AUC) (nanomole*minutes per milliliter).

\section{Results}

Tri-Hydroxyl BAs Exclusively Derived from DCA Oxidations. As shown in Fig. 1, A-C, we found five unknown tri-hydroxyl BA species (TBA05, TBA09, TBA10, TBA13 and TBA18) in the 

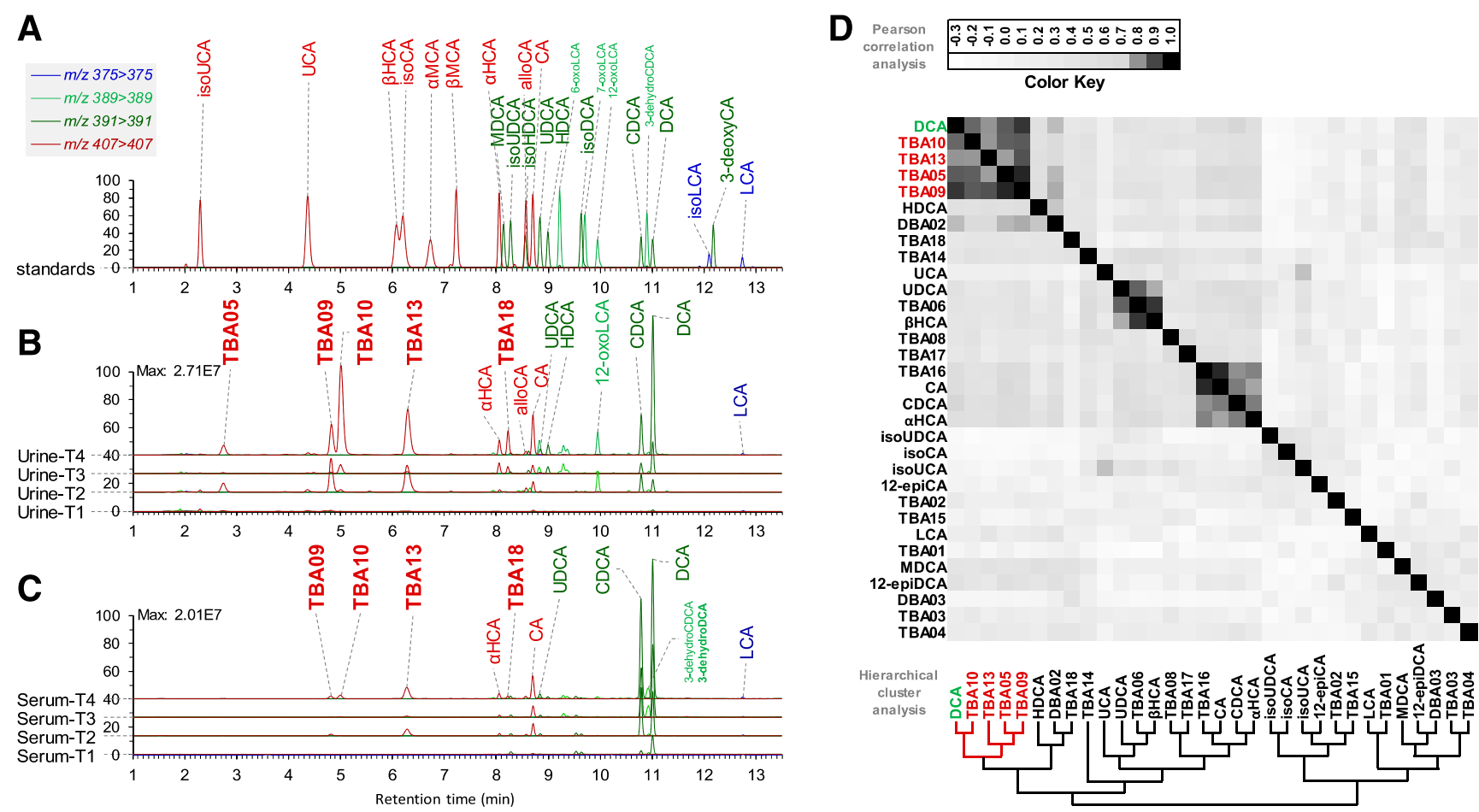

Fig. 1. Unconjugated tri-hydroxyl BAs (TBA05, TBA09, TBA10, TBA13, and TBA18) are biologically associated with DCA. The extracted ion chromatograms of the mixed BA standards, whose abbreviations and structures are summarized in Supplemental Table S1 (A). TBA05, TBA09, TBA10, TBA13, and TBA18 were detected in the 0- to 2-hour postprandial urine sample from a representative healthy subject (B). TBA09, TBA10, TBA13, and TBA18 were detected in the 1-hour postprandial serum sample from the same subject (C). Four aliquots of the same urine and serum samples were prepared without enzymes (T1), with choloylglycine hydrolase (T2), with sulfatase and $\beta$-glucuronidase (T3), and with all three enzymes (T4). The biologic associations of TBA05, TBA09, TBA10, and TBA13 with DCA were highlighted by hierarchical cluster analysis (D) of the Pearson correlation coefficients between the urinary total unconjugated BAs profile in the test population of 58 healthy volunteers (36 men and 22 women).

post-prandial urine and serum of 13 healthy volunteers collected at UNC-CH Hospitals (Zhu et al., 2018). Enzyme digestion techniques demonstrated that they were extensively conjugated, thus, explaining their "invisibility" to those direct analysis techniques without consideration of BA conjugation. The Quad time-of flight MS/MS spectra captured in the digested urine samples showed that they had fragment ions possibly associated with 12-hydroxylation on the skeleton (Lan et al., 2016; Zhu et al., 2018). They were therefore supposed to be structurally associated with DCA and CA, the two major BAs with 12-hydroxylation. Additional analysis of the total BA profiles in spot urine samples from 45 healthy Chinese adults confirmed that they are common BA species in human. Metabolomic analysis of the total urinary BA profiles from 58 healthy adults was employed to examine the biologic associations of the unidentified tri-hydroxyl BAs with known BA species. Despite vast individual differences, the potential biologic relationships were observed using hierarchical cluster analysis of Pearson correlation coefficients between the detected unconjugated BAs. As shown in Fig. 1D, TBA05, TBA09, TBA10, and TBA13 were independently crosscorrelated to DCA $(r>0.75)$, which strengthened the hypothesis that TBA05, TBA09, TBA10 and TBA13 are hydroxylated metabolites of DCA. We subsequently performed in vitro metabolite screening of a series of known unconjugated BAs in human liver microsomes to verify the hypothesis. It was confirmed that these newly detected BAs were not derived from the epimerization of CA (Supplemental Fig. S8) or from hydroxylation of LCA (Supplemental Figs. S9 and S10). They were also not derived from hydroxylation of the other di-hydroxyl BAs including, CDCA, UDCA, isoUDCA, HDCA, isoDCA, MDCA, isoHDCA and 3-deoxyCA (Supplemental Fig. S11-S18). As shown in Supplemental Fig. S7, TBA05,
TBA09, TBA10, TBA13, TBA18, in addition to TBA04, a trihydroxy BA that was detected at trace levels in serum and urine, were characterized as hydroxylated metabolites exclusively from DCA species.

Characterization of the Stereoselective Oxidation of DCA. Besides the $3 \alpha$ - and $12 \alpha$-hydroxyl groups, there is only one unknown oxidation site on the steroid skeleton of TBA04, TBA05, TBA09, TBA10, TBA13 and TBA18. The unusual hydroxylation sites at C-1, C-2, C-4, C-6 and C-19 have been reported in earlier gas chromatography-mass spectrometry-based studies of human BAs and were particularly discussed as being present in early human life (Sjövall et al., 2010). We gratefully acknowledge the contribution from Takashi Iida who shared his negative electrospray ionization/ time-of-flight MS data of some early synthesized compounds in the MASSBANK database (Horai et al., 2010), which enabled us to have a relatively reasonable guide for our own synthetic efforts. By matching the high-definition MS/MS spectra (Fig. 2) and retention data (Fig. 1 and 3 ) of the synthesized standards to those of metabolites captured in vivo or in vitro, TBA04, TBA05, TBA09, TBA10, TBA13 and TBA18 were eventually identified as DCA-19-ol, DCA-6 $\beta$-ol, DCA- $5 \beta$-ol, DCA- $6 \alpha$-ol, DCA- $1 \beta$-ol and DCA- $4 \beta$-ol, respectively. As far as we know, this is the first report confirming the occurrence of DCA- $5 \beta$-ol and DCA-19-ol in humans.

Preliminary fragmentation analysis identified common mass losses corresponding to $\left[\mathrm{M}-\mathrm{H}-\mathrm{H}_{2} \mathrm{O}-\mathrm{CO}_{2}\right]^{-}(\mathrm{m} / \mathrm{z}, 345.3)$ and/or $\left[\mathrm{M}-\mathrm{H}-2 \mathrm{H}_{2} \mathrm{O}-\right.$ $\mathrm{CO}^{-}(\mathrm{m} / z 343.3)$ in the spectra of DCA- $6 \beta-\mathrm{ol}$, DCA- $6 \alpha$-ol, DCA- $1 \beta$-ol and DCA- $4 \beta$-ol. A diagnostic fragment ion, $\left[\mathrm{C}_{19} \mathrm{H}_{27} \mathrm{O}\right]^{-}(\mathrm{m} / z, 271.2)$, was found in the spectra of DCA- $5 \beta$-ol, which is similar as the ring cleavage fragment of $\mathrm{CA},\left[\mathrm{C}_{19} \mathrm{H}_{29} \mathrm{O}_{2}\right]^{-}(\mathrm{m} / \mathrm{z}, 289.2)$. Diagnostic fragment ions associated with other ring-cleavage mechanisms, 
A
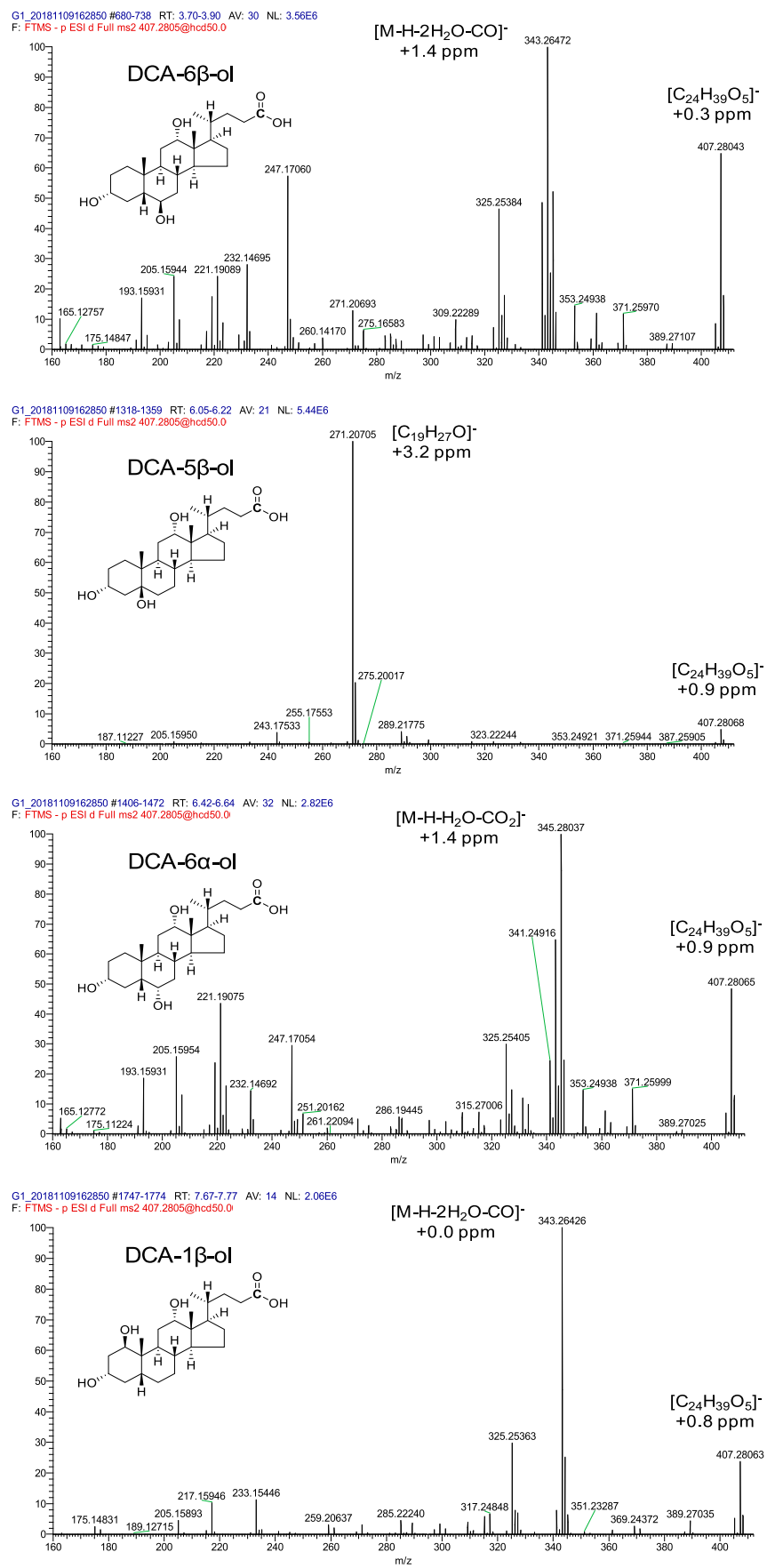

B
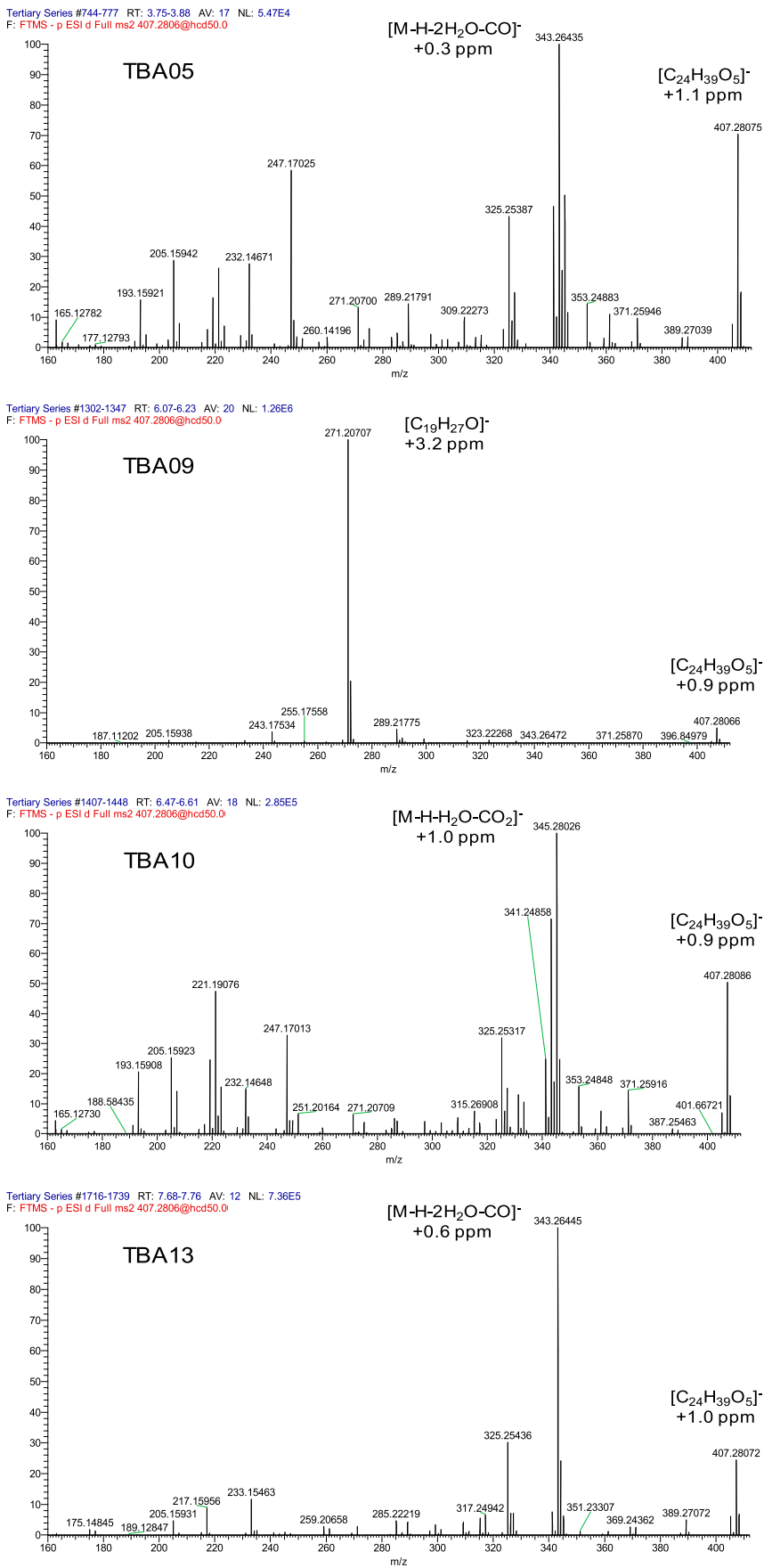

Fig. 2. High-definition MS/MS spectra of the oxidized DCA metabolites captured from the synthesized standards (a) and the metabolites detected in vivo or in vitro (b). All standards were synthesized in the laboratory except 3-dehydroDCA was obtained from TRC (cat. no. O856870). The data of endogenous DCA-6 $\beta$-ol, DCA-5 $\beta$-ol, DCA- $6 \alpha$-ol, DCA-1 $\beta$-ol, and DCA- $4 \beta$-ol were captured from a representative digested urine sample. The in vitro data of DCA-19-ol and 3-dehydroDCA were captured from the DCA incubation samples in human liver microsomes.

$\left[\mathrm{C}_{22} \mathrm{H}_{35} \mathrm{O}_{2}\right]^{-}(\mathrm{m} / \mathrm{z}, 331.3)$ and $\left[\mathrm{C}_{22} \mathrm{H}_{33} \mathrm{O}\right]^{-}(\mathrm{m} / \mathrm{z}, 313.3)$, were detected in the spectra of DCA- $4 \beta$-ol and DCA-19-ol, respectively. These observations were to some extent consistent with the previously identified key role of 12-hydroxylation in the negative fragmentation of unconjugated C24 BAs (Lan et al., 2016). The detailed analysis is to be summarized in our later analytical report.

We have detected both in vivo and in vitro (Figs. 1C and 3A; Supplemental Fig. S19), another major metabolite of DCA, 3-dehydroDCA (Zhu et al., 2018). Consistent with previous reports (Amuro et al., 1986; Deo and Bandiera, 2008, 2009), the 3-dehydrogenation reaction was also observed for LCA, CDCA, UDCA and CA (Supplemental Fig. S20-S23). The 3-dehydrogenation mechanism was proposed to be involved with a $3 \alpha, 3 \beta$-diol intermediate formed by $3 \beta$-hydroxylation, based on the evidence that the incubation of isoDCA in human liver microsomes did not produce 3-dehydroDCA (Bodin et al., 2005). Our work has provided additional evidence for the $3 \beta$-oxidation mechanism because $\mathrm{C} 3-\beta$ was the major oxidation site of 3-deoxyCA (Supplemental Fig. S18). To this end, we have 
A
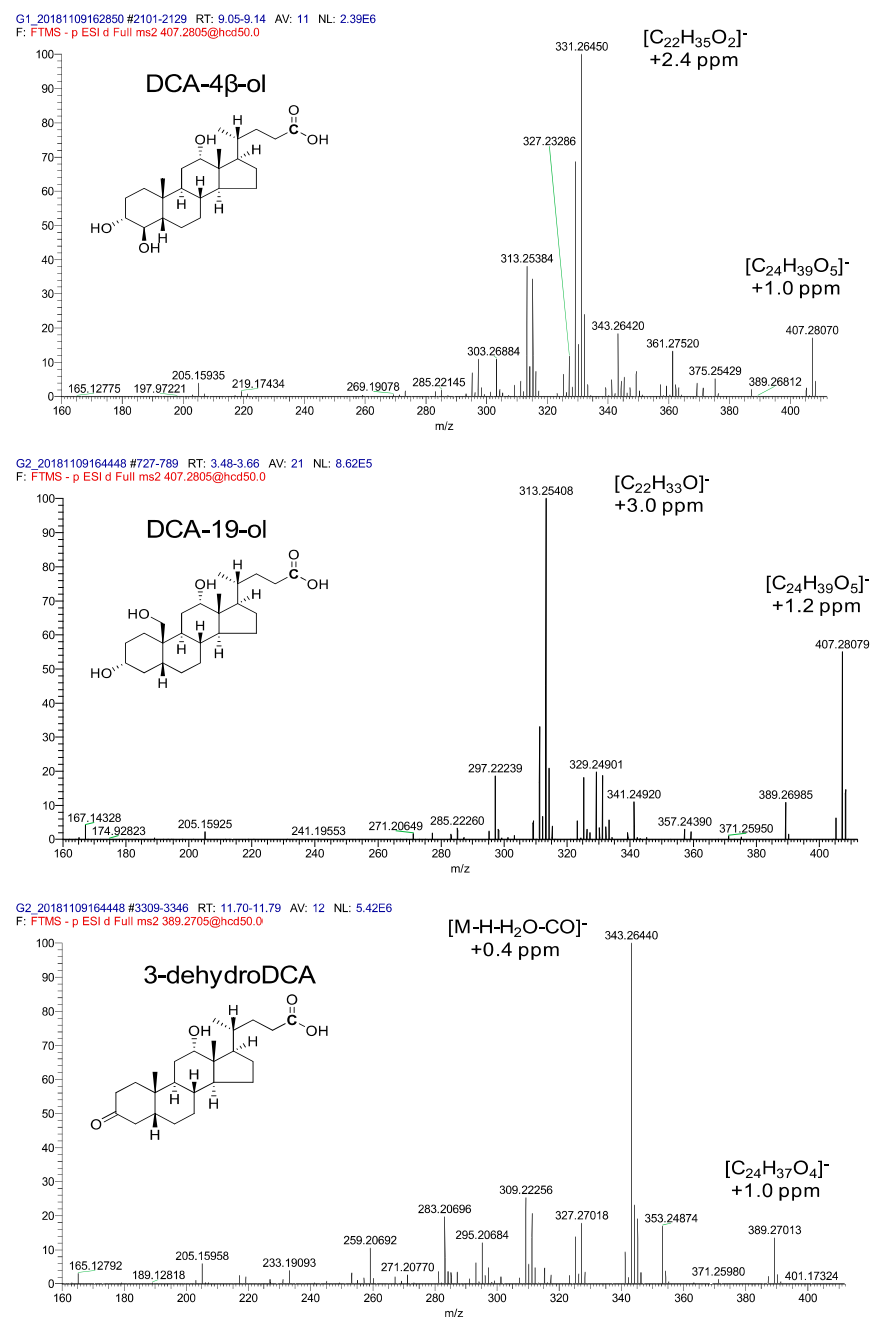

B
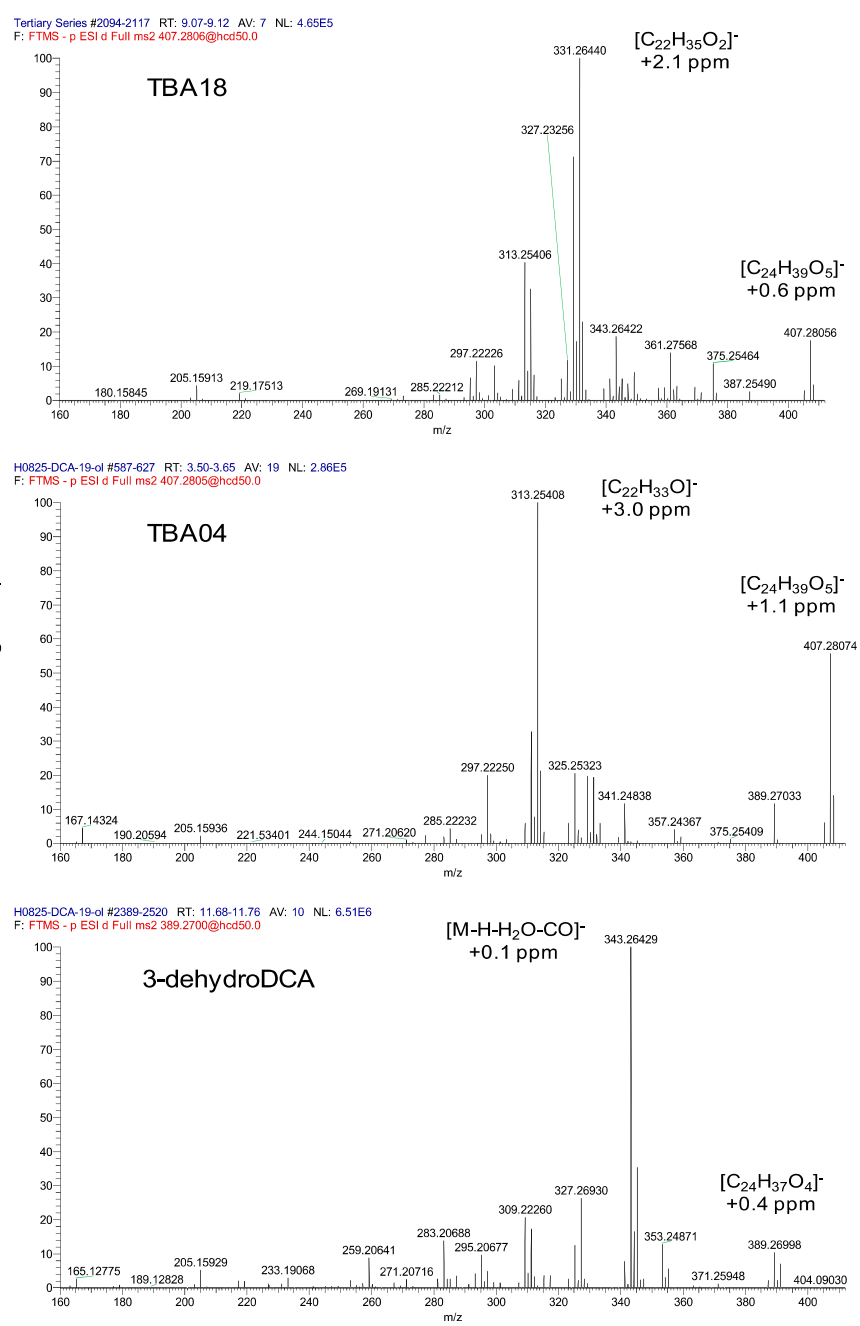

Fig. 2. Continued. provided strong evidence that DCA is regioselectively hydroxylated at $\mathrm{C}-1 \beta,-3 \beta,-4 \beta,-5 \beta,-6 \alpha,-6 \beta$, and -19 . As shown in Fig. $3 \mathrm{C}$, the identified oxidation sites cluster on the same plane around the $5 \beta$-hydrogen. We have compared the stereoselective oxidation rates of DCA in the pooled microsomes prepared from human liver, intestine and kidney. The human kidney microsomes showed no reactivity to DCA oxidations at any sites (data not shown). Our data shows that the DCA oxidations happen primarily in human liver microsomes and secondarily in human intestinal microsomes (Fig. 3D). No formation of DCA-19-ol and DCA- $4 \beta$-ol was observed in human intestinal microsomes.

CYP3A Inhibitors Selectively Inhibit DCA Oxidations in Human Liver Microsomes. A series of in vitro inhibition assays were performed to begin the characterization of the $\mathrm{P} 450$ isoenzymes responsible for DCA oxidations. Figure 3, E and F, shows the inhibitory effects of various P450 inhibitors, either time-dependent or not, on the regioselective oxidations of DCA. No inhibition effects were observed for the selective inhibitors for CYP1A2 (furafylline and $\alpha$-naphthoflavone), CYP2C8 (phenelzine, montelukast, and quercetin), CYP2C9 (sulfaphenazole), and CYP2D6 (quinidine), and the nonselective inhibitors for CYP2A6 (2-PCPA), CYP2C19 (nootkatone), and CYP2E1 (DEDC). Tienilic acid, a selective inhibitor for CYP2C9, showed a mild inhibition to the oxidations at C19 (14\%) and $\mathrm{C} 4-\beta$
(13\%). Thio-TEPA, a nonselective inhibitor for CYP2B6, showed a mild inhibition to the oxidation at $\mathrm{C} 5-\beta$ (12\%). Ticlopidine, a nonselective inhibitor for CYP2C19, showed mild inhibition to the oxidation at $\mathrm{C} 5-\beta(7 \%)$.

Paroxetine $(10 \mu \mathrm{M})$, a selective time-dependent CYP2D6 inhibitor, showed mild inhibition to the oxidations at $\mathrm{C} 3-\beta$ (17\%), $\mathrm{C} 1-\beta(22 \%)$, C5- $\beta$ (30\%), C6- $\alpha$ (7\%), and C6- $\beta$ (26\%). Sertraline $(10 \mu \mathrm{M})$, a nonselective CYP2B6 inhibitor with time-dependent inhibitory effects on CYP3A4 (Masubuchi and Kawaguchi, 2013), showed mild inhibition to the oxidations at $\mathrm{C} 3-\beta(31 \%)$ and $\mathrm{C} 1-\beta$ (28\%). Fluconazole $(10 \mu \mathrm{M})$, a strong inhibitor of CYP2C19 and moderate inhibitor of CYP2C9 and CYP3A, showed mild to moderate inhibition of oxidation at C3- $\beta$ (33\%) and C6- $\beta(23 \%)$. Verapamil (25 $\mu \mathrm{M})$, a selective timedependent CYP3A inhibitor, showed strong inhibition of oxidation at C3- $\beta$ (60\%), C1- $\beta$ (79\%), C5- $\beta$ (85\%), C6- $\alpha$ (65\%), and C6- $\beta$ (100\%) and moderately at $\mathrm{C} 19(27 \%)$ and $\mathrm{C} 4-\beta(37 \%)$. Ketoconazole $(0.5 \mu \mathrm{M})$, an index CYP3A inhibitor, showed strong inhibition of oxidation at $\mathrm{C} 3-\beta$ (71\%), C1- $\beta$ (76\%), C5- $\beta$ (80\%), C6- $\alpha$ (68\%), and C6- $\beta$ (76\%) and, to a lesser extent, at $\mathrm{C} 19(49 \%)$ and $\mathrm{C} 4-\beta(51 \%)$. These results clearly demonstrated that CYP3A is the major isoenzymes responsible for the tertiary stereoselective oxidation of DCA.

CYP3A4 and CYP3A7 Are Responsible for DCA Oxidations Regardless of N-Acylamidation. We investigated DCA oxidation in a 
A

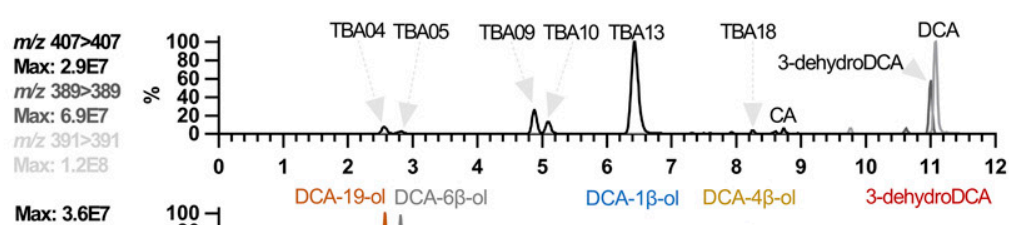

B Max: 3.6E

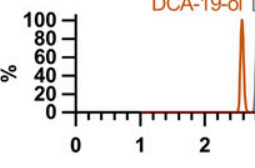

DCA-5B-ol DCA- 0 -

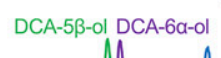

-dehydroDCA

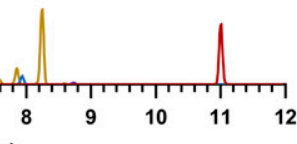

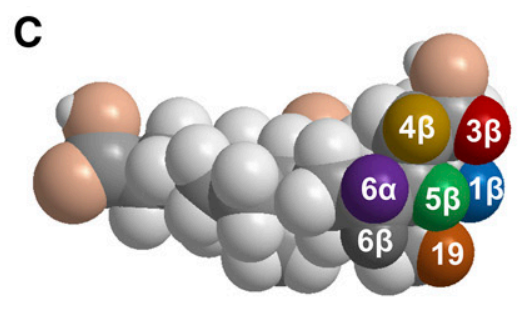

D

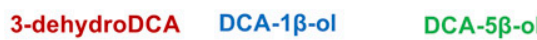

Retention time $(\min )$

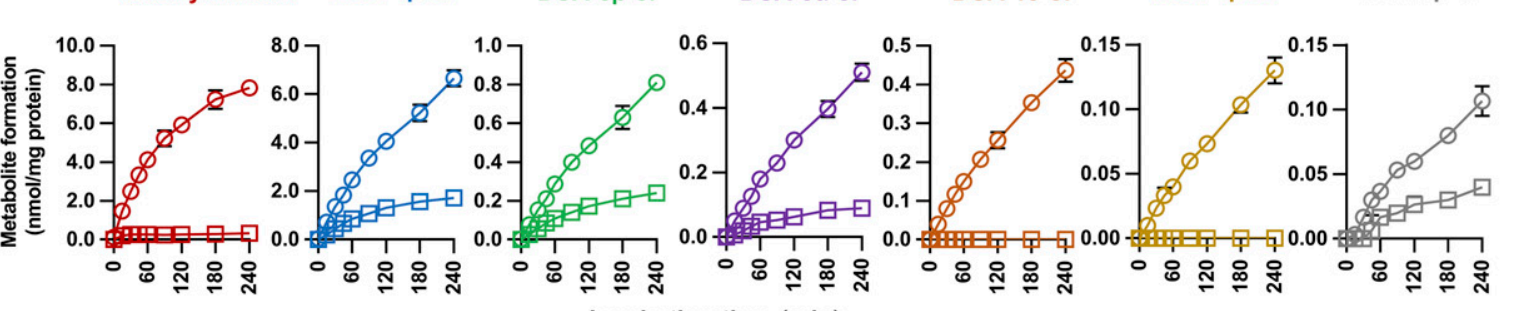

$\mathbf{E}$
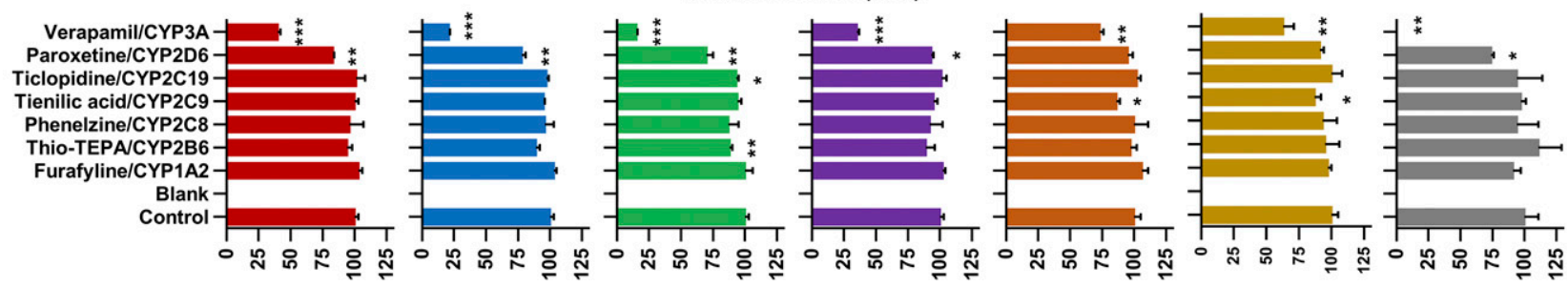

Metabolite formation vs control (\%)

$\mathbf{F}$
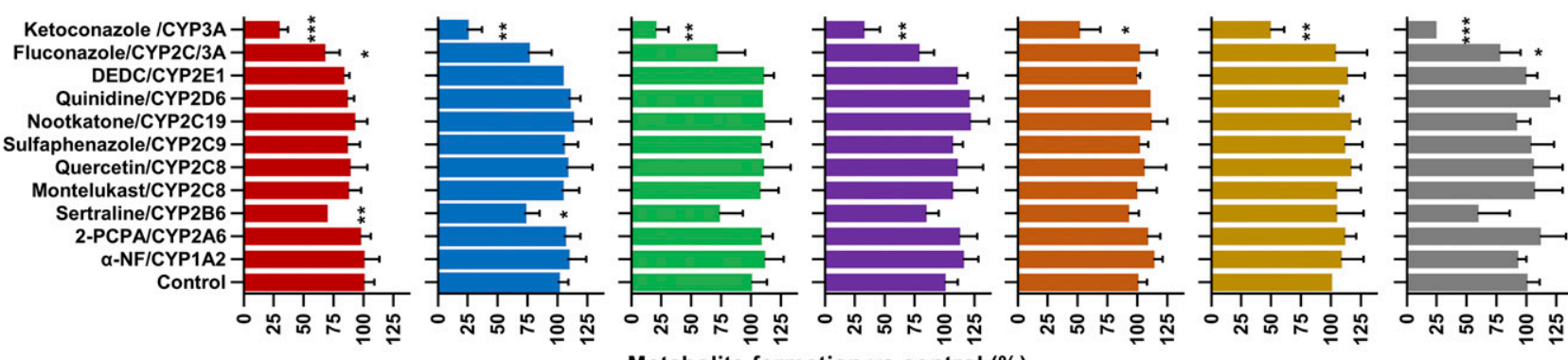

Metabolite formation vs control (\%)

Fig. 3. In vitro regioselective oxidation of DCA in human liver microsomes. TBA04, TBA05, TBA09, TBA10, TBA13, TBA18 ( $/ 2 / 2407>407)$, and 3-dehydroDCA $(\mathrm{m} / z 389>389)$ were detected after incubation of DCA $(\mathrm{m} / z, 391>391)$ in human liver microsomes $(\mathrm{A})$. The retention data of DCA-19-ol, DCA-6 $\beta$-ol, DCA-5 $\beta$-ol, DCA- $6 \alpha$-ol, DCA- $1 \beta$-ol, DCA- $4 \beta$-ol, and 3-dehydroDCA corresponded well with the metabolites of DCA (B). The identified oxidation sites cluster on the same plane around the $5 \beta$-hydrogen in the three-dimensional structure of DCA (C). The metabolite formation kinetics after incubation of $50 \mu \mathrm{M}$ DCA $(n=3$, data shown as mean \pm S.D.) in human liver microsomes and human intestinal microsomes for 240 minutes at a protein level of $0.5 \mathrm{mg} / \mathrm{ml}$ (D). The inhibition of metabolite formation after incubation of $50 \mu \mathrm{M}$ DCA in human liver microsomes for 60 minutes by time-dependent inhibitors $(n=3$, data shown as mean \pm S.D., student $t$ test compared with control: $\left.* P<0.05 ;{ }^{*} P<0.01 ; * * * P<0.001\right)$, including verapamil $(25 \mu \mathrm{M})$, paroxetine $(10 \mu \mathrm{M})$, ticlopidine $(1 \mu \mathrm{M})$, tienilic acid $(10 \mu \mathrm{M})$, phenelzine $(1 \mu \mathrm{M})$, thio-TEPA $(5 \mu \mathrm{M})$, and furafylline $(1 \mu \mathrm{M})(\mathrm{E})$. The inhibition of metabolite formation after incubation of $50 \mu \mathrm{M}$ DCA in human liver microsomes for 60 minutes by selective inhibitors, including ketoconazole $(0.5 \mu \mathrm{M})$, fluconazole $(10 \mu \mathrm{M})$, DEDC $(20 \mu \mathrm{M})$, quinidine $(1 \mu \mathrm{M})$, nootkatone $(1 \mu \mathrm{M})$, sulfaphenazole $(1 \mu \mathrm{M})$, quercetin $(1 \mu \mathrm{M})$, montelukast $(0.5 \mu \mathrm{M})$, sertraline $(10 \mu \mathrm{M}), 2$-PCPA $(0.2 \mu \mathrm{M})$, and $\alpha$-NF $(0.1 \mu \mathrm{M})(\mathrm{F})$.

panel of $\mathrm{rP} 450 \mathrm{~s}(0.5 \mathrm{nmol}$ protein/ml $)$ compared with that in human liver microsomes ( $0.5 \mathrm{mg}$ protein $/ \mathrm{ml})$. As shown in Fig. 4A, CYP3A4 and CYP3A7 showed the highest catalytic activity at all oxidation sites, whereas CYP3A5 showed a much lower activity level of 3-dehydrogenation and trace or no oxidation at the other sites. For the other P450s, except for CYP3A, only trace amounts of 3-dehydroDCA and DCA- $6 \beta$-ol were detected in incubations of CYP2C8. As shown in Supplemental Fig. S24, the specific oxidations of DCA through CYP3A4 and CYP3A7 were consistently observed in two rP450 systems, Supersomes and Bactosomes. The metabolic enzyme phenotyping results were consistent with those of the human liver microsome inhibition assay. We thus concluded that CYP3A4 and CYP3A7 were dominantly responsible for the tertiary oxidation of DCA.
The circulated DCA is conjugated in the liver through $\mathrm{N}$-acyl linkage with either glycine as GDCA or taurine as TDCA. We compared the in vitro metabolite formation of DCA, GDCA, and TDCA in rP450s and human liver microsomes, in which the oxidized metabolites of GDCA and TDCA were detected after being digested by choloylglycine hydrolase (Zhu et al., 2018). Typical ion chromatograms of DCA, GDCA, or TDCA incubated in human liver microsomes, rCYP3A4, rCYP3A5, and rCYP3A7 were shown in Supplemental Fig. S25-S28. Almost the same enzyme specificity with unique contributions of CYP3A4 and CYP3A7 was observed for the oxidation of GDCA and TDCA (Fig. 4). An exception was that the enzyme specificity was lost for $3 \beta$-oxidation of GDCA and TDCA, to whom CYP2E1, 2J2, 4A11, 4F2, 4F3B, and 4F12 demonstrated higher 


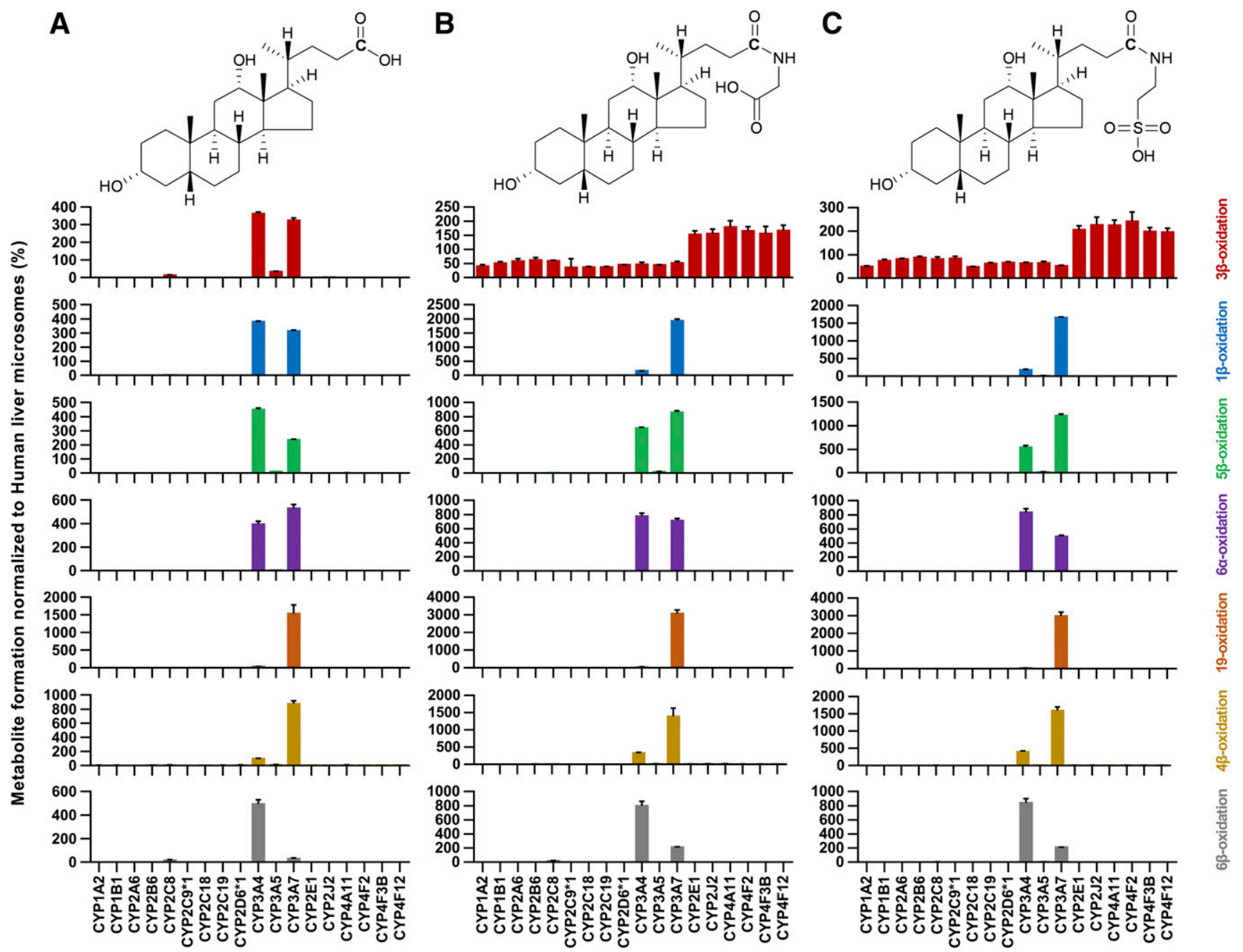

Fig. 4. CYP3A4 and CYP3A7 are responsible for the oxidation of DCA, GDCA, and TDCA. The metabolite formation after incubations of $50 \mu \mathrm{M}$ DCA (A), GDCA (B), and TDCA (C) for 60 minutes in a panel of $18 \mathrm{rCYPs}(\mathrm{CYP} 1 \mathrm{~A} 2,1 \mathrm{~B} 1,2 \mathrm{~A} 6,2 \mathrm{~B} 6,2 \mathrm{C} 8,2 \mathrm{C} 9 * 1,2 \mathrm{C} 18,2 \mathrm{C} 19,2 \mathrm{D} 6 * 1,3 \mathrm{~A} 4,3 \mathrm{~A} 5,3 \mathrm{~A} 7,2 \mathrm{E} 1,2 \mathrm{~J} 2,4 \mathrm{~A} 11,4 \mathrm{~F} 2,4 \mathrm{~F} 3 \mathrm{~B}$, and 4F12; $50 \mathrm{pmol}$ protein $/ \mathrm{ml})$ were compared with the data of human liver microsomes $(0.5 \mathrm{mg}$ protein/ml acquired in parallel. The oxidized metabolites of GDCA and TDCA were detected after being digested by choloylglycine hydrolase. Data were shown as mean \pm S.D. $(n=3)$.

reactivity than the other tested P450s. The regioselective activities of CYP3A4, CYP3A5, and CYP3A7 to oxidize DCA, GDCA, and TDCA are comparatively highlighted in Fig. 5. CYP3A4 demonstrated a reverse activity toward $1 \beta$ - and $6 \alpha$-oxidation of DCA with and without the $\mathrm{N}$-acylamidation. Except for the oxidation at $\mathrm{C}-3 \beta$, CYP3A4 oxidized DCA predominantly at $\mathrm{C}-1 \beta$, whereas GDCA and TDCA were oxidized by CYP3A4 most frequently at C- $6 \alpha$. Unlike CYP3A4, CYP3A7 exhibited a nearly consistent regioselectivity for DCA, GDCA, and TDCA. N-acylamidation of DCA significantly increased the CYP3A7-mediated $1 \beta, 5 \beta, 6 \alpha, 19$, and $4 \beta$-hydroxylation, with the highest activity observed for TDCA. The activities of CYP3A7 for some reactions were significantly greater than those of CYP3A4. The metabolite formation ratios of CYP3A7/CYP3A4 decreased in the following order: TDCA 19-hydroxylation (81.4), GDCA 19-hydroxylation (70.9), DCA 19-hydroxylation (43.8), GDCA $1 \beta$ hydroxylation (11.8), TDCA $1 \beta$-hydroxylation (9.1), and DCA $4 \beta$ hydroxylation (8.7). Based on enzyme specificity data, it was believed that these reactions are promising as possible novel in vitro probe reactions for CYP3A7 activity. In summary, it was clearly demonstrated that CYP3A4 and CYP3A7 were responsible for the regioselective oxidation of DCA, regardless of its $\mathrm{N}$-acylamidation status.
Conjugation Pattern of Tertiary BAs. Based on the characterized tertiary BA metabolism pathways, we showed the host-gut microbial cometabolism for the downstream metabolism of CA (Fig. 6A) and CDCA (Fig. 6B) in 13 healthy adults during the 2 hour-postprandial period after a high-fat diet. Enzyme digestion techniques demonstrated that all the tertiary BAs were extensively conjugated, resulting in an easily neglected level for their free unconjugated forms, particularly in serum samples. Despite the tertiary BAs having a low serum level, DCA- $6 \alpha$-ol, DCA- $1 \beta$-ol, DCA- $5 \beta$-ol, and HDCA were determined as the major tertiary species presenting with total urinary levels comparable with primary and secondary BAs in all 13 subjects. By using the enzyme-digestion technique, the total level of a BA may be categorized in four fractions (Fig. 6C): the free unconjugated form, the amidated form, the glucuronidated/sulfated form, and the "double-conjugates" linked with both glycine/taurine and glucuronide/sulfate. The latter two fractions are both glucuronidated/sulfated species. The average percentage conjugation patterns of serum AUC and urine level for each BA were shown in Fig. 6, A and B. Some data were not available because detections were with a trace level $(<10 \mathrm{nM})$ in some samples. For example, DCA-19-ol was not found in any serum samples and was detected in only 2 of 13 urine samples. 


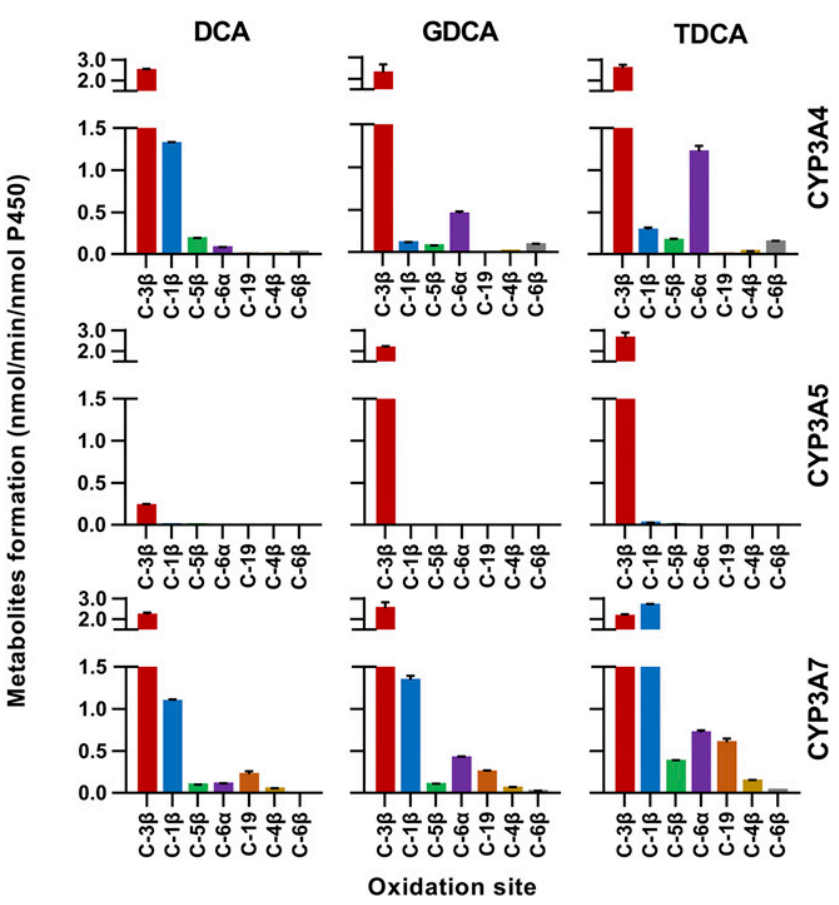

Fig. 5. Regioselectivity of CYP3A4, CYP3A5, and CYP3A7 for the oxidation of DCA, GDCA, and TDCA. Metabolite formation after incubations of $50 \mu \mathrm{M}$ DCA, GDCA, and TDCA for 60 minutes in $\mathrm{rCYP} 3 \mathrm{~A} 4,3 \mathrm{~A} 5$, and $3 \mathrm{~A} 7$ (50 $\mathrm{pmol}$ protein $/ \mathrm{ml}$ ). The oxidized metabolites of GDCA and TDCA were detected after being digested by choloylglycine hydrolase. Data were shown as mean \pm S.D. $(n=3)$.

DCA- $6 \alpha$-ol and HDCA, the $6 \alpha$-hydroxylated metabolites of DCA and LCA, were the most heavily glucuronidated/sulfated tertiary species. The glucuronidated/sulfated fractions of DCA- $6 \alpha-$ ol and HDCA were significantly more elevated than DCA and LCA, respectively. HDCA circulated in serum and excreted in urine mainly in glucuronidated/sulfated forms and DCA- $6 \alpha$-ol existed mainly in "double-conjugated" forms. A similar conjugation pattern was observed for DCA- $4 \beta$-ol and DBA03, an unidentified LCA hydroxylated metabolite that was detected in 6 of 13 subjects. In comparison, DCA- $1 \beta$-ol and DCA- $5 \beta$-ol, which did not undergo glucuronidation/sulfation as significantly as DCA- $6 \alpha$-ol did, were excreted in urine, mainly in amidated forms. The glucuronidated/ sulfated fractions of DCA- $1 \beta$-ol and DCA- $5 \beta$-ol in urine were both significantly lower than that of DCA. DCA- $6 \beta$-ol and MDCA, the $6 \beta$-hydroxylated metabolites of DCA and LCA, were also excreted in urine mainly in amidated forms. Therefore, we deduced that tertiary $6 \alpha$-oxidation facilitates glucuronidation/sulfation metabolism, whereas $1 \beta$ - and $5 \beta$-oxidation of DCA species do not. Further studies are required to investigate the glucuronidation and sulfation mechanisms of tertiary BA species under the different conjugation patterns of them.

Tertiary Oxidation Facilitates the Renal Excretion of DCA Species. The free and total 0- to 2-hour urinary levels and time-dependent serum concentrations (mean \pm S.E.M.) of each BA detected by $\mathrm{T} 1$ and T4 are comparatively showed in Fig. 6 and Supplemental Table S2. The primary BAs, CDCA and CA, are synthesized from cholesterol, N-acylamidated, secreted into the bile, and recycled in the enterohepatic system. The free and total levels of CDCA and CA were significantly higher in serum than urine, manifesting a conservative renal disposition for the primary BAs to facilitate their enrichment in the enterohepatic system. After postprandial release into the intestine, most CDCA and CA (95\%) are recovered in the bile by the ileal apical sodium-dependent bile acid transporter, the sinusoidal $\mathrm{Na}^{+}$-taurocholate cotransporting polypeptide, and the canalicular bile salt export pump, and the remaining 5\% enters the lower gut, where they are further metabolized by gut bacteria into secondary BAs. The major metabolic pathway for secondary BAs is deconjugation of the amidated forms by bacteria with bile salt hydrolase activity and the subsequent 7-dehydroxylation of unconjugated forms by bacteria that carries the bai gene. The resulting LCA and DCA are lipophilic and exogenous to the host. Most of the LCA is excreted in feces because it is much less soluble than DCA, which is consistent with the relative total AUC of DCA/CA $(3.68 \pm 1.08$, mean \pm S.E.M., $n=13)$ being about 40 times higher than that of LCA/CDCA $(0.09 \pm 0.01)$; however, the free and total levels of DCA were also significantly higher in serum than urine, indicating that DCA is also inclined to be recycled in the enterohepatic system, as seen for CA and CDCA. Therefore, there might be another mechanism to regulate BA homeostasis by disposing the "toxic" secondary BAs, particularly, DCA which is less hydrophobic and has a much greater exposure than LCA.

In contrast to CA and DCA, the total levels of major tertiary metabolites of DCA (DCA- $6 \alpha$-ol, DCA- $1 \beta$-ol, DCA- $5 \beta$-ol, and DCA$4 \beta$-ol) were significantly higher in urine than serum, indicating that they are preferentially excreted in urine compared with the primary and secondary BAs. We calculated the apparent renal clearance data based on the total urinary excretion data and the total serum AUC data during the 2 hour-postprandial period. The effects of conjugation metabolism (glucuronidation, sulfation, and $\mathrm{N}$-acylamidation) on renal clearance were included in the apparent clearance data. As shown in Fig. 6D, the tertiary BAs demonstrated significantly higher apparent renal clearances than did the primary and secondary BAs, particularly for the downstream metabolites of DCA. In this regard, we believed that tertiary BA metabolism functions, at least in part, in regulating the BA pool size by facilitating the renal excretion of secondary BAs. Accordingly, the urinary total BA profile is an ideal footprint to understand the functional status of the host-gut microbial cometabolism of BAs in biomedical and transitional researches.

\section{Discussion}

This work has characterized the CYP3A-catalyzed metabolic pathway of tertiary BAs in the host-gut microbial cometabolism network of BAs in human adults (Fig. 6). Our work confirmed that the previously presumed "unusual" oxidized metabolites of DCA are ubiquitously occurring in the adult population but are often undetected in serum owing to their extensive conjugation metabolism, which allows them to undergo renal excretion. It was also determined in this study that CYP3A4, the most abundant P450 isoenzyme in adult liver, was responsible for the tertiary oxidations of DCA, GDCA, and TDCA. The fact that fetal-specific CYP3A7 plays an important role in the tertiary oxidation of DCA, GDCA, and TDCA may also explain why those BAs with "unusual" oxidation sites were preferably found in neonates, infants, and pregnant women (Sjövall et al., 2010). Because of challenges in differentiating metabolic contributions from host or gut microbiomes in human subjects, more studies in germ-free animals are required to confirm whether gut bacteria participate the oxidation metabolism of DCA species. Based on the analysis of the postprandial BA profiles in serum and urine, it is believed that the tertiary BA metabolism functions, at least in part, to facilitate the renal excretion of secondary BAs and accordingly regulate the BA pool size and composition. As suggested by the in vitro inhibition data (Fig. 3, E and F), the inhibition of tertiary BA metabolism might 


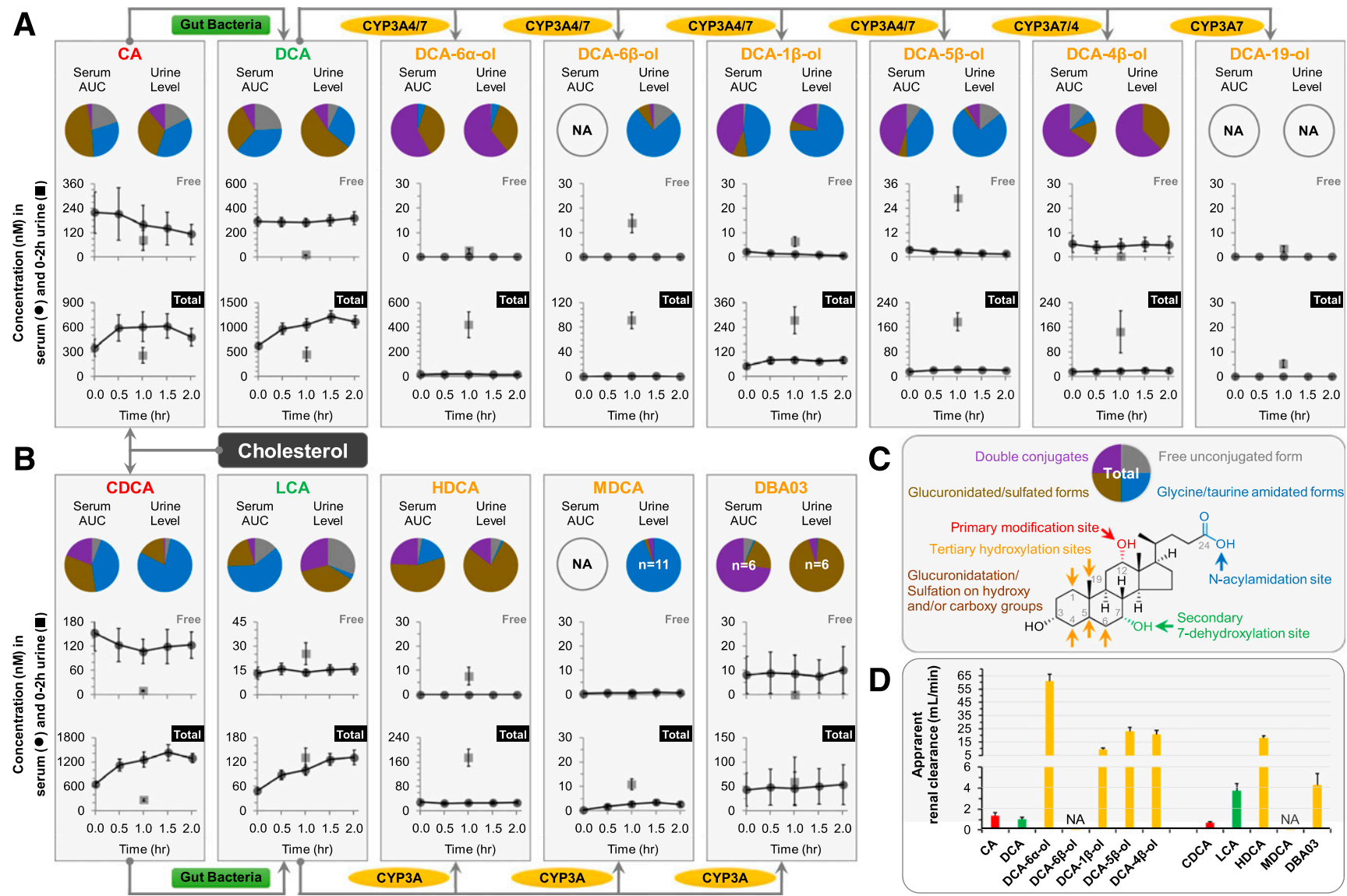

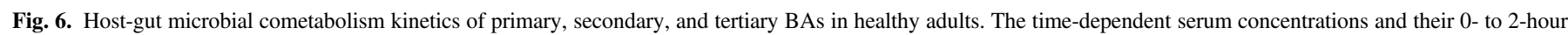

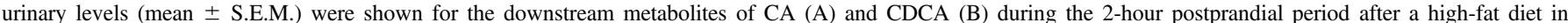

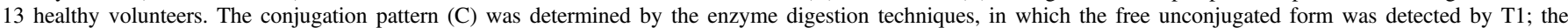

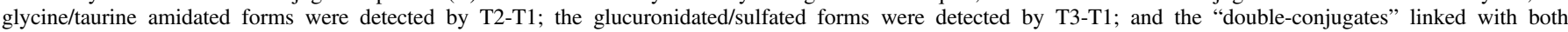

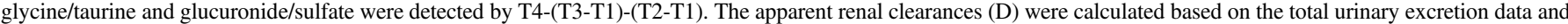
the total serum AUC data during the 2-hour postprandial period.

be pathologically associated with cholestasis-associated liver injury induced by strong CYP3A inhibitors, such as ketoconazole (Stricker et al., 1986).

Enzyme digestion techniques were used in this work to investigate the conjugation metabolism of BAs (Zhu et al., 2018). The indirect method may not provide information of conjugation sites and pathways but clearly present different conjugation patterns of the investigated BA species. Based on composite analysis of the renal clearance data and conjugation pattern data in Fig. 6, we propose that the tertiary oxidation of DCA species contributes to host disposition of DCA species in two major ways. On one hand, the CYP3A4/7 mediated $6 \alpha$-oxidation of DCA species facilitates the glucuronidation/sulfation metabolism and the subsequent renal excretion. Similar phenomena have been reported for the UDP-glucuronosyltransferase (UGT) 2B4- catalyzed glucuronidation and the subsequent urinary excretion of HDCA, the $6 \alpha$-hydroxylated metabolite of LCA (Sacquet et al., 1983; Parquet et al., 1985; Radomińska-Pyrek et al., 1987; Pillot et al., 1993). On the other hand, the CYP3A4/7 catalyzed $1 \beta$ - and $5 \beta$-oxidation of DCA species does not help glucuronidation/sulfation but may directly facilitate the renal secretion. UGT1A3, UGT2B4, UGT2B7, and sulfotransferase $2 \mathrm{~A} 1$ have been reported to be involved in the conjugation metabolism of B As (Trottier et al., 2006). More efforts are required to investigate glucuronidation, sulfation and tubular secretion mechanisms of the hydroxylated metabolites of DCA species.
CYP3A4 is considered of great importance in general pharmacology, and CYP3A7 has become increasingly important in pediatric pharmacology (Stevens, 2006). Despite the high degree of sequence identity between the genes encoding human CYP3A4 and CYP3A7, it is still incompletely understood how they adapt to and regioselectively oxidize a wide range of compounds (Sevrioukova and Poulos, 2017). A lack of probe reactions is acknowledged as one of the key problems. Beyond the recently proposed DCA $1 \beta$-hydroxylation (Hayes et al., 2016), this work has provided the regioselective oxidations of DCA, GDCA, and TDCA as novel in vitro probe reactions for CYP3A4 and CYP3A7 activities. As shown in Fig. 3C, CYP3A4 and CYP3A7 both show $\mathrm{C}-\mathrm{H}$ activation capacities around the $5 \beta$-hydrogen on the steroid skeleton of DCA, GDCA, and TDCA. Relative to CYP3A4, CYP3A7 favored the oxidations at C-19, C- $4 \beta$, and C-1 $\beta$. The 19-hydroxylation of DCA, GDCA, and TDCA demonstrated an overwhelming CYP3A7 selectivity than the currently used CYP3A7 probe reactions, $16 \alpha$-hydroxylation of dehydroepiandrosterone and the $2 \alpha$-hydroxylation of testosterone (Leeder et al., 2005). Therefore, future studies in combination with protein crystallography and simulation of molecular docking will be useful in promoting our understanding of the structural basis for the regioselective oxidation mechanisms of CYP3A4 and CYP3A7.

The fetal-specific CYP3A7 is also significantly expressed in a subset of adult livers partially associated with the CYP3A7*1C allele (Sim et al., 2005). In comparison with the reported data of human fetal livers 
$(234.8 \pm 123.1 \mathrm{pmol} / \mathrm{mg}$ microsomal protein, mean \pm S.D., $n=54)$ (Leeder et al., 2005), the CYP3A7 protein was detected in approximately one of 10 adult livers $(n=59)$, amounting to $24-90 \mathrm{pmol} / \mathrm{mg}$ of microsomal protein (Sim et al., 2005). Recent studies have increasingly showed that gene variances of CYP3A7 are associated with various clinical outcomes, including bone mineral density in postmenopausal women independent of serum levels of dehydroepiandrosterone sulfate (Bácsi et al., 2007); decreased dehydroepiandrosterone sulfate levels in women with polycystic ovary syndrome (Goodarzi et al., 2008); adverse outcomes in chronic lymphocytic leukemia, breast, and lung cancer (Johnson et al., 2016); reduced levels of 2-hydroxylation pathway estrogen metabolites (Sood et al., 2017); and maternal determinants of fetal growth independent of fetal genetics (Beaumont et al., 2018). There is, therefore, an increasing need for a specific in vivo CYP3A7 biomarker. We preliminarily analyzed the ratios of the total urinary level of CYP3A7-oxidized metabolites to that of DCA as potential biomarkers for CYP3A7 activities (Supplemental Fig. S29). Using the criterion that the urinary DCA-4 $\beta$-ol/DCA ratio must be higher than $0.5[0.26 \pm 0.36$ (mean \pm S.D.), 0.03-2.35 (min-max), 0.17 (median)], about 6 of 58 healthy volunteers demonstrated a high $4 \beta$-oxidation capacity, consistent with the reported frequency of CYP3A7 protein analysis. Interestingly, DCA-19-ol, the most selectively oxidized metabolite of DCA catalyzed by CYP3A7 in vitro, was not detected in any serum samples and detected with only a trace level in a small part of urine samples. This phenomenon might be associated with either the polymorphism of CYP3A4 and CYP3A7 or the potential subsequent metabolism of 19-hydroxylated metabolites in vivo. More studies are required to decipher the in vitro-in vivo inconsistency of the 19-hydroxylation of DCA species.

CYP3A4 and CYP3A7 are the P450 isoenzymes dominantly expressed in adult and fetal liver, respectively. Not only is there a postnatal expression change from CYP3A7 toward CYP3A4 occurring rapidly in the first month and progressively during the first year after birth (Saghir et al., 2012), but there is also great interindividual and intraindividual variability in their expressions in adult liver (Zanger and Schwab, 2013). Functional genetic variations, such as CYP3A7*1C, CYP3A7*1B, and CYP3A4*22, explain only a small part of variability in expression and activity of CYP3A4 and CYP3A7 (Burk et al., 2002; Sim et al., 2005; Wang et al., 2011). The lack of commonly occurring genetic variations has led to many efforts to elucidate the constitutive and inducible factors responsible for CYP3A4 regulation. In the field of drug metabolism, it has been well established that CYP3A4 is highly inducible through activation of farnesoid $\mathrm{X}$ receptor (Gnerre et al., 2004), vitamin D receptor (Drocourt et al., 2002), pregnane X receptor (Goodwin et al., 1999), and constitutive androstane receptor (Goodwin et al., 2002) by xenobiotics, such as drugs, carcinogens, pollutants, and dietary supplements (Zanger and Schwab, 2013), all of which may be categorized as "artificial environmental factors." Without consideration of these artificial factors, the inherent driving force for the regulation of CYP3A4 and CYP3A7 has not been fully established. Given that both CYP3A7 and CYP3A4 participate in the oxidative metabolism of endogenous ligands for nuclear receptors, such as steroid hormones (Ohmori et al., 1998; Niwa et al., 2015) and retinoic acids (Chen et al., 2000; Marill et al., 2002; Shimshoni et al., 2012), it has been generally accepted that variances of these endogenous signal molecules and genetic variations of the corresponding nuclear receptors constitute the inherent regulation factors. This work has extended the function of CYP3A to the metabolism of the secondary BAs, DCA and LCA, which have also been characterized as agonists of farnesoid $\mathrm{X}$ receptor, pregnane X receptor and vitamin D receptor (Makishima et al., 1999, 2002; Parks et al., 1999). These gut bacteria-derived signal molecules are "exogenous" to the host, and therefore may be classified as "inherent environmental factors." In fact, the time course of postnatal regulation of CYP3A7 toward CYP3A4 is intriguingly consistent with the colonization of infant gut bacteria responsible for secondary BA production, such as Bacteroides, Clostridium, Lactobacillus, Bifidobacterium, and Listeria spp., are responsible for BA deconjugation and Clostridium and Eubacterium spp. responsible for $7 \alpha$-dehydroxylation (Gérard, 2013; Ridlon et al., 2016). We therefore hypothesize that the ontogeny of CYP3A4 and CYP3A7 responsible for tertiary BAs metabolism might be associated with a postnatal protective mechanism in response to the stress of secondary BAs.

In conclusion, this work disclosed the continuum mechanism in the host-gut microbial cometabolism of BAs in human adults. The primary BAs are synthesized from cholesterol in host liver, the secondary BAs are modified from primary BAs by gut microbiota, and the recovered secondary BAs are remodified as tertiary BAs in host liver. CYP3A4 and CYP3A7 were shown to be predominantly responsible for the tertiary regioselective oxidation of DCA, GDCA, and TDCA at C- $1 \beta$, $-3 \beta,-4 \beta,-5 \beta,-6 \alpha,-6 \beta$, and -19 on the steroid skeleton. The disclosed tertiary BA metabolic pathways have extended the biologic function of CYP3A4 and CYP3A7 from being an important DME that acts to detoxify pharmacologic agents to that of having an inherent role in the host response to the stress of secondary BAs. In summary, we propose that discovering the inherent roles of DMEs in host-gut microbial cometabolism, along with the colonization, development, homeostasis, and dysbiosis of the symbiotic microbiota will become an important future scientific endeavor for the prevention of drug and environment-induced toxicity.

\section{Acknowledgments}

We thank Dr. Takashi Iida (Nihon University) for the gift of isoUCA and contributions for the MS data in the public online resources MASSBANK.

\section{Authorship Contributions}

Participated in research design: Liu, Jia, Lan.

Conducted experiments: Zhang, Chen, Zhu, Yin, Su, Miao, Brouwer, Lan. Contributed new reagents or analytic tools: Gao, $\mathrm{Wu}, \mathrm{H}$. Chen, $\mathrm{Xu}$.

Performed data analysis: Zhang, Ni, Lan.

Wrote or contributed to the writing of the manuscript: Zhang, Jia, Lan.

\section{References}

Amuro Y, Yamade W, Yamamoto T, Kudo K, Fujikura M, Maebo A, Hada T, and Higashino K (1986) Isocholic acid formation from 7 alpha, 12 alpha-dihydroxy-3-keto-5 beta-cholanoic acid with human liver enzyme. Biochim Biophys Acta 879:362-368.

Araya Z and Wikvall K (1999) 6alpha-hydroxylation of taurochenodeoxycholic acid and lithocholic acid by CYP3A4 in human liver microsomes. Biochim Biophys Acta 1438:47-54.

Bácsi K, Kósa JP, Borgulya G, Balla B, Lazáry A, Nagy Z, Horváth C, Speer G, and Lakatos P (2007) CYP3A7*1C polymorphism, serum dehydroepiandrosterone sulfate level, and bone mineral density in postmenopausal women. Calcif Tissue Int 80:154-159.

Beaumont RN, Warrington NM, Cavadino A, Tyrrell J, Nodzenski M, Horikoshi M, Geller F, Myhre R, Richmond RC, Paternoster L, et al.; Early Growth Genetics (EGG) Consortium (2018) Genome-wide association study of offspring birth weight in 86577 women identifies five novel loci and highlights maternal genetic effects that are independent of fetal genetics. Hum Mol Genet 27:742-756.

Bodin K, Lindbom U, and Diczfalusy U (2005) Novel pathways of bile acid metabolism involving
CY CYP3A4. Biochim Biophys Acta 1687:84-93.

Buffie CG, Bucci V, Stein RR, McKenney PT, Ling L, Gobourne A, No D, Liu H, Kinnebrew M, Viale A, et al. (2015) Precision microbiome reconstitution restores bile acid mediated resistance to Clostridium difficile. Nature 517:205-208.

Burk O, Tegude H, Koch I, Hustert E, Wolbold R, Glaeser H, Klein K, Fromm MF, Nuessler AK, Neuhaus P, et al. (2002) Molecular mechanisms of polymorphic CYP3A7 expression in adult human liver and intestine. J Biol Chem 277:24280-24288.

Chen H, Fantel AG, and Juchau MR (2000) Catalysis of the 4-hydroxylation of retinoic acids by cyp3a7 in human fetal hepatic tissues. Drug Metab Dispos 28:1051-1057.

Dawson PA and Karpen SJ (2015) Intestinal transport and metabolism of bile acids. J Lipid Res $\mathbf{5 6}$ $1085-1099$.

de Aguiar Vallim TQ, Tarling EJ, and Edwards PA (2013) Pleiotropic roles of bile acids in metabolism. Cell Metab 17:657-669.

Deo AK and Bandiera SM (2008) Identification of human hepatic cytochrome p450 enzymes involved in the biotransformation of cholic and chenodeoxycholic acid. Drug Metab Dispos 36:1983-1991.

Deo AK and Bandiera SM (2009) 3-ketocholanoic acid is the major in vitro human hepatic microsomal metabolite of lithocholic acid. Drug Metab Dispos 37:1938-1947. 
Donia MS and Fischbach MA (2015) Human microbiota: small molecules from the human microbiota. Science 349:1254766.

Drocourt L, Ourlin JC, Pascussi JM, Maurel P, and Vilarem MJ (2002) Expression of CYP3A4, CYP2B6, and CYP2C9 is regulated by the vitamin D receptor pathway in primary human hepatocytes. J Biol Chem 277:25125-25132.

Ferslew BC, Xie G, Johnston CK, Su M, Stewart PW, Jia W, Brouwer KL, and Barritt AS IV (2015) Altered bile acid metabolome in patients with nonalcoholic steatohepatitis. Dig Dis Sci 60:3318-3328.

Gérard P (2013) Metabolism of cholesterol and bile acids by the gut microbiota. Pathogens 3: $14-24$.

Gnerre C, Blättler S, Kaufmann MR, Looser R, and Meyer UA (2004) Regulation of CYP3A4 by the bile acid receptor FXR: evidence for functional binding sites in the CYP3A4 gene. Pharmacogenetics 14:635-645.

Gonzalez FJ and Nebert DW (1990) Evolution of the P450 gene superfamily: animal-plant 'warfare', molecular drive and human genetic differences in drug oxidation. Trends Genet 6:182-186.

Goodarzi MO, Xu N, and Azziz R (2008) Association of CYP3A7*1C and serum dehydroepiandrosterone sulfate levels in women with polycystic ovary syndrome. J Clin Endocrinol Metab 93:2909-2912.

Goodwin B, Hodgson E, D'Costa DJ, Robertson GR, and Liddle C (2002) Transcriptional regulation of the human CYP3A4 gene by the constitutive androstane receptor. Mol Pharmacol 62: 359-365.

Goodwin B, Hodgson E, and Liddle C (1999) The orphan human pregnane X receptor mediates the transcriptional activation of CYP3A4 by rifampicin through a distal enhancer module. Mol Pharmacol 56:1329-1339.

Gustafsson J, Andersson S, and Sjövall J (1985) Bile acid metabolism during development: metabolism of taurodeoxycholic acid in human fetal liver. Biol Neonate 47:26-31.

Hayes MA, Li XQ, Grönberg G, Diczfalusy U, and Andersson TB (2016) CYP3A specifically catalyzes $1 \beta$-hydroxylation of deoxycholic acid: characterization and enzymatic synthesis of a potential novel urinary biomarker for CYP3A activity. Drug Metab Dispos 44:1480-1489.

Hayes MA, Roberts I, Grönberg G, Lv K, Lin B, Bergare J, and Elmore CS (2017) Synthesis of 1 $\beta$ hydroxydeoxycholic acid in $\mathrm{H}-2$ and unlabeled forms. J Labelled Comp Radiopharm 60 : 221-229.

Horai H, Arita M, Kanaya S, Nihei Y, Ikeda T, Suwa K, Ojima Y, Tanaka K, Tanaka S, Aoshima $\mathrm{K}$, et al. (2010) MassBank: a public repository for sharing mass spectral data for life sciences. J Mass Spectrom 45:703-714.

Iida T, Komatsubara I, Chang FC, Goto J, and Nambara T (1991a) Potential bile acid metabolites. 17. Synthesis of 2 beta-hydroxylated bile acids. Steroids 56:114-122.

Iida T, Momose T, Chang FC, Goto J, and Nambara T (1989) Potential bile acid metabolites. XV. Synthesis of 4 beta-hydroxylated bile acids; unique bile acids in human fetal bile. Chem Pharm Bull (Tokyo) 37:3323-3329.

Iida T, Tamaru T, Chang FC, Goto J, and Nambara T (1991b) Potential bile acid metabolites. XVIII. Synthesis of stereoisomeric 3,6,12 alpha-trihydroxy-5 beta-cholanoic acids. J Lipid Res 32:649-658.

Iida T, Yamaguchi T, Nakamori R, Hikosaka M, Mano N, Goto J, and Nambara T (2001) A highly efficient, stereoselective oxyfunctionalization of unactivated carbons in steroids with dimethyldioxirane. J Chem Soc, Perkin Trans 1. 0:2229-2236.

Inagaki T, Moschetta A, Lee YK, Peng L, Zhao G, Downes M, Yu RT, Shelton JM, Richardson JA, Repa JJ, et al. (2006) Regulation of antibacterial defense in the small intestine by the nuclear bile acid receptor. Proc Natl Acad Sci USA 103:3920-3925.

Johnson N, De Ieso P, Migliorini G, Orr N, Broderick P, Catovsky D, Matakidou A, Eisen T, Goldsmith C, Dudbridge F, et al. (2016) Cytochrome P450 allele CYP3A $7 * 1 \mathrm{C}$ associates with adverse outcomes in chronic lymphocytic leukemia, breast, and lung cancer. Cancer Res 76: 1485-1493.

Kawamata Y, Fujii R, Hosoya M, Harada M, Yoshida H, Miwa M, Fukusumi S, Habata Y, Itoh T, Shintani Y, et al. (2003) A G protein-coupled receptor responsive to bile acids. J Biol Chem $\mathbf{2 7 8}$ 9435-9440.

Kurosawa T, Nomura Y, Mahara R, Yoshimura T, Kimura A, Ikegawa S, and Tohma M (1995) Synthesis of 19-hydroxylated bile acids and identification of 3 alpha,7 alpha,12 alpha, 19tetrahydroxy-5 beta-cholan-24-oic acid in human neonatal urine. Chem Pharm Bull (Tokyo) 43: $1551-1557$.

Lan K, Su M, Xie G, Ferslew BC, Brouwer KL, Rajani C, Liu C, and Jia W (2016) Key role for the 12-hydroxy group in the negative ion fragmentation of unconjugated $\mathrm{C} 24$ bile acids. Anal Chem 88:7041-7048

Leeder JS, Gaedigk R, Marcucci KA, Gaedigk A, Vyhlidal CA, Schindel BP, and Pearce RE (2005) Variability of CYP3A7 expression in human fetal liver. J Pharmacol Exp Ther 314: 626-635.

Makishima M, Lu TT, Xie W, Whitfield GK, Domoto H, Evans RM, Haussler MR, and Mangelsdorf DJ (2002) Vitamin D receptor as an intestinal bile acid sensor. Science 296: $1313-1316$.

Makishima M, Okamoto AY, Repa JJ, Tu H, Learned RM, Luk A, Hull MV, Lustig KD, Mangelsdorf DJ, and Shan B (1999) Identification of a nuclear receptor for bile acids. Science 284:1362-1365.

Marill J, Capron CC, Idres N, and Chabot GG (2002) Human cytochrome P450s involved in the metabolism of 9-cis- and 13-cis-retinoic acids. Biochem Pharmacol 63:933-943.

Maruyama T, Miyamoto Y, Nakamura T, Tamai Y, Okada H, Sugiyama E, Nakamura T, Itadani H, and Tanaka K (2002) Identification of membrane-type receptor for bile acids (M-BAR). Biochem Biophys Res Commun 298:714-719.

Masubuchi Y and Kawaguchi Y (2013) Time-dependent inhibition of CYP3A4 by sertraline, a selective serotonin reuptake inhibitor. Biopharm Drug Dispos 34:423-430.
Nebert DW (1990) Drug metabolism: growth signal pathways. Nature 347:709-710.

Nebert DW (1991) Proposed role of drug-metabolizing enzymes: regulation of steady state levels of the ligands that effect growth, homeostasis, differentiation, and neuroendocrine functions. Mol Endocrinol 5:1203-1214.

Nebert DW, Jones JE, Owens J, and Puga A (1988) Evolution of the P450 gene superfamily. Prog Clin Biol Res 274:557-576.

Niwa T, Murayama N, Imagawa Y, and Yamazaki H (2015) Regioselective hydroxylation of steroid hormones by human cytochromes P450. Drug Metab Rev 47:89-110.

Ohmori S, Fujiki N, Nakasa H, Nakamura H, Ishii I, Itahashi K, and Kitada M (1998) Steroid hydroxylation by human fetal CYP3A7 and human NADPH-cytochrome P450 reductase coexpressed in insect cells using baculovirus. Res Commun Mol Pathol Pharmacol 100:15-28.

Parks DJ, Blanchard SG, Bledsoe RK, Chandra G, Consler TG, Kliewer SA, Stimmel JB, Willson TM, Zavacki AM, Moore DD, et al. (1999) Bile acids: natural ligands for an orphan nuclear receptor. Science 284:1365-1368.

Parquet M, Pessah M, Sacquet E, Salvat C, Raizman A, and Infante R (1985) Glucuronidation of bile acids in human liver, intestine and kidney: an in vitro study on hyodeoxycholic acid. FEBS Lett 189:183-187.

Pillot T, Ouzzine M, Fournel-Gigleux S, Lafaurie C, Radominska A, Burchell B, Siest G, and Magdalou J (1993) Glucuronidation of hyodeoxycholic acid in human liver: evidence for a selective role of UDP-glucuronosyltransferase 2B4. J Biol Chem 268:25636-25642.

Radomińska-Pyrek A, Zimniak P, Irshaid YM, Lester R, Tephly TR, and St Pyrek J (1987) Glucuronidation of 6 alpha-hydroxy bile acids by human liver microsomes. J Clin Invest 80:234-241.

Ridlon JM, Harris SC, Bhowmik S, Kang DJ, and Hylemon PB (2016) Consequences of bile salt biotransformations by intestinal bacteria. Gut Microbes 7:22-39.

Ridlon JM, Kang DJ, and Hylemon PB (2006) Bile salt biotransformations by human intestinal bacteria. J Lipid Res 47:241-259.

Russell DW (2003) The enzymes, regulation, and genetics of bile acid synthesis. Annu Rev Biochem 72:137-174.

Sacquet E, Parquet M, Riottot M, Raizman A, Jarrige P, Huguet C, and Infante R (1983) Intestinal absorption, excretion, and biotransformation of hyodeoxycholic acid in man. J Lipid Res 24: 604-613.

Saghir SA, Khan SA, and McCoy AT (2012) Ontogeny of mammalian metabolizing enzymes in humans and animals used in toxicological studies. Crit Rev Toxicol 42:323-357.

Sevrioukova IF and Poulos TL (2017) Structural basis for regiospecific midazolam oxidation by human cytochrome P450 3A4. Proc Natl Acad Sci USA 114:486-491.

Shimshoni JA, Roberts AG, Scian M, Topletz AR, Blankert SA, Halpert JR, Nelson WL, and Isoherranen N (2012) Stereoselective formation and metabolism of 4-hydroxy-retinoic acid enantiomers by cytochrome p450 enzymes. J Biol Chem 287:42223-42232.

Sim SC, Edwards RJ, Boobis AR, and Ingelman-Sundberg M (2005) CYP3A7 protein expression is high in a fraction of adult human livers and partially associated with the CYP3A7*1C allele. Pharmacogenet Genomics 15:625-631.

Sjövall J, Griffiths WJ, Setchell KDR, Mano N, and Goto J (2010) Analysis of Bile Acids, New York, Springer.

Sood D, Johnson N, Jain P, Siskos AP, Bennett M, Gilham C, Busana MC, Peto J, Dos-SantosSilva I, Keun HC, et al. (2017) CYP3A7*1C allele is associated with reduced levels of 2-hydroxylation pathway oestrogen metabolites. Br J Cancer 116:382-388.

Stevens JC (2006) New perspectives on the impact of cytochrome P450 3A expression for pediatric pharmacology. Drug Discov Today 11:440-445.

Stricker BH, Blok AP, Bronkhorst FB, Van Parys GE, and Desmet VJ (1986) Ketoconazoleassociated hepatic injury: a clinicopathological study of 55 cases. J Hepatol 3:399-406.

Theriot CM, Koenigsknecht MJ, Carlson PE Jr, Hatton GE, Nelson AM, Li B, Huffnagle GB, Z Li J, and Young VB (2014) Antibiotic-induced shifts in the mouse gut microbiome and metabolome increase susceptibility to Clostridium difficile infection. Nat Commun 5:3114.

Trottier J, Milkiewicz P, Kaeding J, Verreault M, and Barbier O (2006) Coordinate regulation of hepatic bile acid oxidation and conjugation by nuclear receptors. Mol Pharm 3:212-222.

Trülzsch D, Roboz J, Greim H, Czygan P, Rudick J, Hutterer F, Schaffner F, and Popper H (1974) Hydroxylation of taurolithocholate by isolated human liver microsomes. I. Identification of metabolic product. Biochem Med 9:158-166.

Vavassori P, Mencarelli A, Renga B, Distrutti E, and Fiorucci S (2009) The bile acid receptor FXR is a modulator of intestinal innate immunity. J Immunol 183:6251-6261.

Wahlström A, Sayin SI, Marschall HU, and Bäckhed F (2016) Intestinal crosstalk between bile acids and microbiota and its impact on host metabolism. Cell Metab 24:41-50.

Wang D, Guo Y, Wrighton SA, Cooke GE, and Sadee W (2011) Intronic polymorphism in CYP3A4 affects hepatic expression and response to statin drugs. Pharmacogenomics $J$ 11:274-286.

Yin S, Su M, Xie G, Li X, Wei R, Liu C, Lan K, and Jia W (2017) Factors affecting separation and detection of bile acids by liquid chromatography coupled with mass spectrometry in negative mode. Anal Bioanal Chem 409:5533-5545.

Zanger UM and Schwab M (2013) Cytochrome P450 enzymes in drug metabolism: regulation of gene expression, enzyme activities, and impact of genetic variation. Pharmacol Ther 138:103-141.

Zhu P, Zhang J, Chen Y, Yin S, Su M, Xie G, Brouwer KLR, Liu C, Lan K, and Jia W (2018) Analysis of human $\mathrm{C} 24$ bile acids metabolome in serum and urine based on enzyme digestion of conjugated bile acids and LC-MS determination of unconjugated bile acids. Anal Bioanal Chem 410:5287-5300.

Address correspondence to: Dr. Ke Lan, West China School of Pharmacy, Sichuan University, No.17 People's South Road, Chengdu, 610041, China. E-mail: lanwoco@scu.edu.cn; or Dr. Wei Jia, University of Hawaii Cancer Center, 701 llalo Street, Honolulu, HI 96813. E-mail: wjia@cc.hawaii.edu 